\title{
Modeling Effects of Stochastic Stray Currents from D.C. Traction on Corrosion Hazard of Buried Pipelines
}

\author{
Jan Szymenderski ${ }^{*}+{ }^{+}$, Wojciech Machczyński ${ }^{\dagger}$ and Krzysztof Budnik ${ }^{\dagger}$ \\ Institute of Electrical Engineering and Electronics, Faculty of Electrical Engineering, Poznan University of \\ Technology, Piotrowo 3A, 60-965 Poznan, Poland; wojciech.machczynski@put.poznan.pl (W.M.); \\ krzysztof.budnik@put.poznan.pl (K.B.) \\ * Correspondence: jan.szymenderski@put.poznan.pl; Tel.: +48-61-665-28-38 \\ t These authors contributed equally to this work.
}

Received: 24 September 2019; Accepted: 27 November 2019; Published: 30 November 2019

\begin{abstract}
The main problems discussed in the article concern the analysis of the phenomenon of stray currents generated by electric D.C. traction currents. These currents flow in the ground and, when they encounter an underground metal structure, can lead to the acceleration of electrochemical corrosion. There is a stochastic phenomenon that depends on many factors such as the position of the traction vehicle along the route or the current drawn by it from the traction network. The presented research concerns the use of probabilistic methods to analyze this phenomenon. The proposed algorithm allows determining the occurrence of electrochemical-pipeline corrosion risk for geometrically complex traction-pipeline systems, including many random variables and corrosion phenomena. The non-deterministic solution to such an interdisciplinary problem is an element of novelty.
\end{abstract}

Keywords: stochastic stray current; D.C. traction; Monte Carlo procedure; earth return circuits; stray current corrosion

\section{Introduction}

Stray currents flowing into the ground from D.C. electric traction return circuits (rail and tram) are still the greatest corrosion risk for steel objects operating underground, such as pipelines or tanks. Despite that, as a result of standardization activities (e.g., [1,2]), several modern solutions have been introduced to everyday technical practices, such as requirements concerning the limiting of stray current leakage from rails to the ground or the protection of metal structures against external electric interactions. The randomly changing direction and intensity of stray currents, and the stochastic interaction on corrosion processes on metal underground structures in zones of harmful interaction of these currents, have forced the application of appropriate tools for analysis of these phenomena.

"Stray current" refers to all types of electric currents that branch off from working circuits and close their flow through conductors not intended for this purpose. A special case are stray currents flowing into the ground. They flow not only through the soil layer, but also into metallic structures (e.g., pipelines and cable shields). In places where a current flows from metal (pipeline) towards the ground, the electrochemical-corrosion process is accelerated. On the basis of Faraday's law, it can be concluded that a 1 A current can dissolve $10 \mathrm{~kg}$ of iron per year. The impact of elapsing current from different systems is widely known (electrical traction, welding equipment, accumulators, galvanizing, etc.). It is considered that the most dangerous stray currents come from electric traction where rails are grounded over the entire circumference length of the operating return element. Because the longitudinal resistance of the rails is not equal to zero, and the resistance 
between rail and ground is not infinitely great, the need to stray currents into the ground always accompanies any such circumference. Technically reasonable limits restrict the flow of these currents to the ground. Therefore, the structure and condition of the traction system are parameters that determine the intensity of stray currents. Track repairs and reconstruction, if they are to reduce stray currents, increase resistance for leakage currents to the ground. The term "stray" is related to the random character of electrical-traction return currents because direction and intensity at a given location depend on many factors. In practice, it is a stochastic process, with all the consequences that arise from this.

The effects of stray D.C. currents on underground metal structures (pipelines) result in electrochemical reactions on the metal surface. In places where the current flows from the pipeline to the ground, there is an anode reaction of metal dissolution; in places where the current flows from the ground to the pipeline, there is a cathodic reaction of oxygen reduction. The corrosion attack is localized in the anodic zone and starts with the formation of pits. In some cases, accelerated pitting and leaks in the pipeline may occur. This may threaten the safety of the pipeline operation, and operators and may even cause an environmental disaster. The general nature of the problem of the effects of D.C. stray currents on nearby pipelines is schematically illustrated in Figure $1[3,4]$.
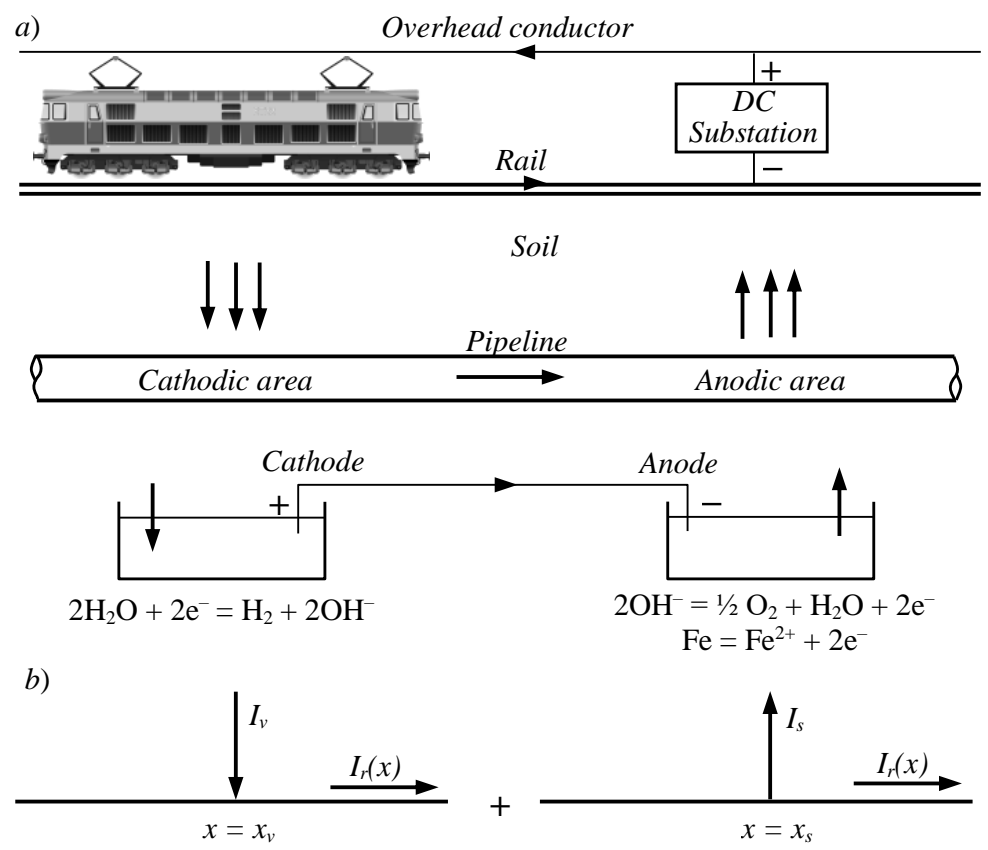

Figure 1. Railway stray-current schematic diagram: (a) real railway system; and (b) equivalent ground-return circuit model.

Estimation of the effects of stray currents on underground pipelines is possible on the basis of knowledge of the density of the current flowing from the pipeline and the overpotential value at the metal/soil electrolyte interface (in electrochemistry, overpotential is the difference in electrode potential when a current is flowing compared to when no current flows). The nature of stray currents coming from traction is highly random, and the direction and intensity of the return depends on many factors. Analysis in this case is difficult and requires appropriate computational algorithms. Previous studies on this issue include many simplifications and assumptions are based on a deterministic approach with restrictions on vehicle movement and their varying load. This is problematic in the analysis of this phenomenon in large urban areas where heavy traffic and diverse vehicle dynamics can result in significant simulation deviation of the actual state.

The "field approach", e.g., the Boundary Element Method, can be used to model the electrochemical polarization that occurs on the subjected structure [5-7]. On the other hand, 
the "electric circuit" approach, based on ground-return circuit theory [8-30], is more suitable for modeling extended structures (pipelines and cables).

There are several steps of modeling and assessment of the impact of D.C. stray currents on nearby pipelines using the circuit approach:

1. development of a model (a model with distributed parameters or with lumped parameters) of electric-traction rails supplied with traction substation current and electric currents drawn by electric locomotives without taking into account (deterministic model) or with taking into account vehicle movement (stochastic model);

2. development of a model (a model with distributed parameters or a model with lumped parameters) of an underground pipeline coupled with an electric-traction rail model powered by traction substation current and currents drawn by electric locomotives without consideration (deterministic model) or with taking into account vehicle movement (stochastic model); and

3. development of a model of the pipeline's response to the impact of stray currents (without taking into account or with taking into account electrochemical phenomena at the metal-soil electrolyte interface).

In the literature, there are few types of electric-circuit approaches to solve the modeling problem of stray-current effects generated by electrified D.C. railways on buried pipelines: the deterministic model (no electrochemistry) [10-19], the dynamic model (no electrochemistry) [20-23], the deterministic model coupled with the electrochemical model [31], the dynamic model coupled with the electrochemical model [25], and the stochastic model without (no electrochemistry) [26] and coupled with electrochemical model [27].

The aim of the work is to present a complete method of investigating the problem of electrochemical corrosion caused by stray currents using computer simulations and mathematical modeling. The methods of analysis used so far are based on deterministic assumptions. The authors propose to include some random variables by using the Monte Carlo algorithm similar to Lucca [26], but with the difference that the presented model takes into account nonlinear electrochemical phenomena and allows problem analysis for traction networks and pipelines with complex geometry.

Application of the presented method allows calculating parameters such as rail longitudinal current, leakage current, potential, primary ground potential, and pipeline response, i.e., shift of pipeline potential (polarization and overpotential) produced by stochastic stray currents in an underground pipeline of complicated geometry. The calculation model was built on the basis of a deterministic model (one scenario for a specific vehicle position and load, $t=$ const.) in combination with electrode kinetics (polarization phenomenon). Different scenarios were analyzed using the Monte Carlo method (locomotive load current and position were random variables). The paper presents two calculation models for determining the response of the underground pipeline to the electric field produced by D.C. stray currents. The first (analytical model) is based on modeling ground-return circuits as circuits with distributed parameters. The second (approximate) uses the circuit model with lumped parameters. The use of the analytical method is limited to only simple cases (mainly due to the duration of calculations). However, the obtained results using the analytical method can be used as a basis for testing approximate numerical models.

The aim of the work was to present a general idea of modeling the influence of stochastic D.C. stray currents on nearby pipelines. Therefore, many simplifying assumptions have been used in the work. One of the more important assumptions is the replacement of the railway track with an equivalent rail laid on the ground surface. It was out of scope of the paper to conduct thorough parametric analysis of the rail-pipeline system. However, the proposed simulation model (lumped-parameter model) enables the introduction and consideration of such parameters of electric traction as type of tracks, frequently spaced substations, cross-bonding, rail resistivity, use of insulated track fasteners, rail boots, improved coatings, maintaining a continuous electrical path, or isolating the rail in the yards.

Another simplified assumption concerns soil characteristics: in the study, it was assumed to be homogeneous, but the calculation method could be generalized to also consider more complex soil 
structures (e.g., stratified soil in horizontal layers). In this case, suitable formulas for the per unit length electrical parameters of the railway track and pipeline as well as of the ground potential would have to be applied.

In a certain number of cases, such simplifications do not allow realistically modeling the railway track-pipeline system and to correctly predict the level of potential and current distribution along a buried pipeline in stray-current areas. Therefore, one has to adopt a very general tool that treats the D.C. railway system and the pipeline as one system composed of two systems that are mutually coupled. The disadvantage related to this approach is that one has to deal with a very large network with many nodes and branches, and with the consequent computational burden. In many real situations, it is possible to simplify the problem by decoupling the influencing and influenced systems. In most cases, currents flowing in rails are much higher than the ones relevant to the pipeline, so the reaction from the pipeline on the rail system can be neglected. Such an assumption may be questionable in some cases where the ground has very high resistivity, and the pipeline is poorly insulated from the soil and very close to the railway route.

In the Monte Carlo method applied two random variables: the position and current of the vehicle are used. It should be noted that in general not only vehicle position and its load current present stochastic characteristics but also other physical parameters such as earth conductivity and rail shunt conductance; in reality, such quantities have a certain degree of randomicity resulting from seasonal changes as soil moisture content, tracks and ballast ageing, etc.

In this study, simplified assumptions were considered as valid, and the proposed calculation method, even if approximated, allowed dealing with the following majority of real cases:

- complex geometrical layouts of both D.C. traction and pipeline;

- nonhomogeneities of affected pipeline (variations in pipe diameter and insulating coating characteristics, and presence of earthing electrodes and insulating joints);

- nonhomogeneities of the track system; and

- $\quad$ stochastic character of D.C. stray currents.

The proposed calculation method can be subdivided into two main steps on the basis of the relevant numerical solution to the transmission-line model with distributed and lumped parameters:

- determination of relevant quantities to the D.C. traction as if the pipeline would not exist, and evaluation of the pipeline response (electric and electrochemical) to the interference using a deterministic approach; and

- evaluation of pipeline corrosion risk using the Monte Carlo procedure to take into account the stochastic character of the interference.

Finally, to sum up, it is worth remarking that, in the study, the pipeline response (pipeline overpotential) to D.C. stray currents as a function of time has not been analysed. This approach is usually used in the analysis of corrosion risks caused by stray currents, and is extensively described in the literature. In contrast to this approach, a simulation method assuming random character of stray currents, using appropriate electrical equivalent models of earth return circuits involved (railway rails and pipeline) in combination with the Monte Carlo procedure and taking into account electrochemical phenomena occurring at the metal-soil electrolyte interface has been proposed. The developed method allows determining the probability of occurrence of anode zones (at risk of corrosion) along the pipeline laid near the direct current electrical traction, assuming that the position of the electric locomotives and the current drawn by the locomotives are random variables. This is an interdisciplinary problem at the interface between electrical engineering (earth return circuits theory, electrical traction, and non-deterministic network analysis) and electrochemistry (stray current corrosion and kinetics of electrode processes: Butler-Volmer equation). The solution to such an interdisciplinary problem is an element of novelty. 


\section{Produced Current and Potential Along Rail by Current Energization}

\subsection{Electric Potential of Rail Modeled as a Circuit with Distributed Parameters}

According to earth-return circuit theory, a rail route can be modeled by an equivalent rail-single conductor with ground return lying on the ground surface [3]. Details of distributed parameters of this circuit can be found in $[3,4,28,32,33]$. The equivalent rail is energized by currents supplied by a substation and a vehicle (load), respectively.

It was shown by Machczynski [4] that, in the case of a finite-length straight rail, open-circuited on both ends $\left(x_{1}\right.$ and $\left.x_{2}\right)$, and with current energization $I_{S}$ at point $x_{s}$, rail current $I_{r}$ can be determined as a function of the abscissa from equation

$$
I_{r}(x)=\frac{I_{s}}{2}\left[-\operatorname{sgn}\left(x-x_{s}\right) e^{-\Gamma_{r}\left|x-x_{s}\right|}-\frac{\cosh \Gamma_{r}\left(x_{2}-x_{s}\right)}{\sinh \Gamma_{r} L} e^{\Gamma_{r} x_{1}} e^{-\Gamma_{r} x}+\frac{\cosh \Gamma_{r}\left(x_{s}-x_{1}\right)}{\sinh \Gamma_{r} L} e^{-\Gamma_{r} x_{2}} e^{\Gamma_{r} x}\right],
$$

where $\Gamma_{r}$ is the equivalent rail-propagation constant and $L=x_{2}-x_{1}$ denotes rail length. Potential along the rail with per unit length shunt conductance $Y_{r}$ can next be calculated from the following relationship:

$$
V_{r}(x)=-\frac{1}{Y_{r}} \frac{d I_{r}(x)}{d x}
$$

Assuming the linearity of the system considered in determination of resultant current and potential along the rail with a number of current energizations, the superposition principle can be used.

\subsection{Electric Potential of Rail Modeled as Circuit with Lumped Parameters}

The analytical method presented in Section 2.1 for solving the problem requires the use of appropriate numerical methods for solving linear differential equations. This increases the required time for calculations, especially when the rail layout is geometrically complicated. Assuming a segment of length $\mathrm{dl}$ of the equivalent rail to be homogeneous (e.g., $Z_{r}, Y_{r}=$ const.), it is possible to model the circuit by a chain of $\pi$-two ports, as shown in Figure $2[10,13]$, where a current source represents current energization.

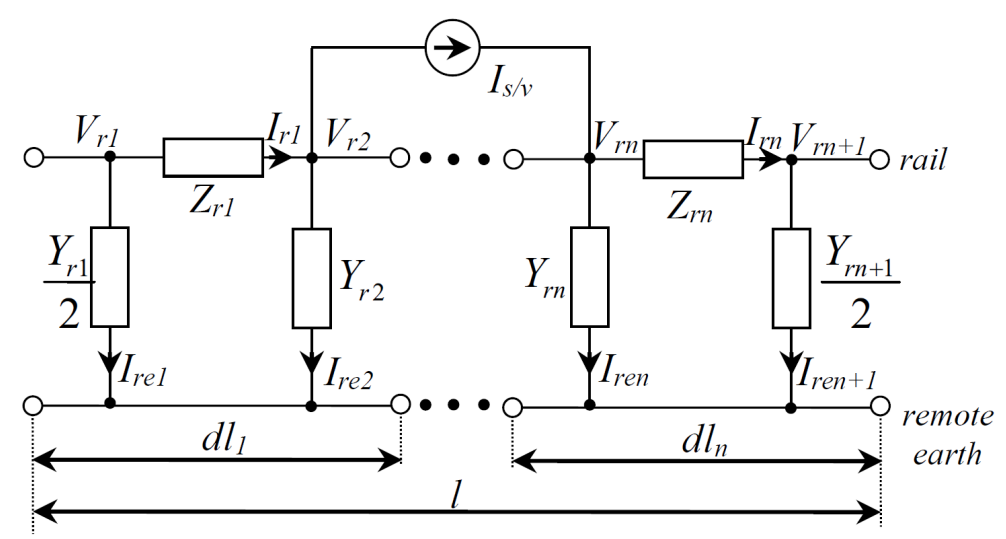

Figure 2. $\pi$-two-port model of rail with a current source representing current energization.

The entire length of the rail can be divided into elementary sections with different electrical parameters or different lengths. Nodes and branches were defined in the model. Their number can be arbitrary; if the number of nodes is too small, the calculation error is too large to successfully apply this method. Exemplary simulations for a straight section of rail with electrical parameters $R_{r}=0.02 \Omega / \mathrm{km}$, $G_{r}=0.76 \mathrm{~S} / \mathrm{km}$ and length $l=10 \mathrm{~km}$ energized by the vehicle $\left(x_{v}=7.5 \mathrm{~km}\right)$ and substation $\left(x_{s}=2.5 \mathrm{~km}\right)$ with current $I=1$ A are shown in Figures 3 and 4 . On the basis of the presented simulation results, 
it can be stated that the length of a single segment should not be greater than $2 \%$ of the total length of the simulated earth-return circuit. For more geometrically complicated systems, the number of nodes can be optimized using appropriate methods (e.g., genetic algorithm). Nodal analysis is a method that can be used to calculate rail current and potential. Current in the rail is calculated using equation

$$
I_{r n}=\frac{V_{n}-V_{n+1}}{Z_{r n}}
$$

and leakage current from the rail with

$$
I_{r e n}=V_{r n} \cdot Y_{r n}
$$

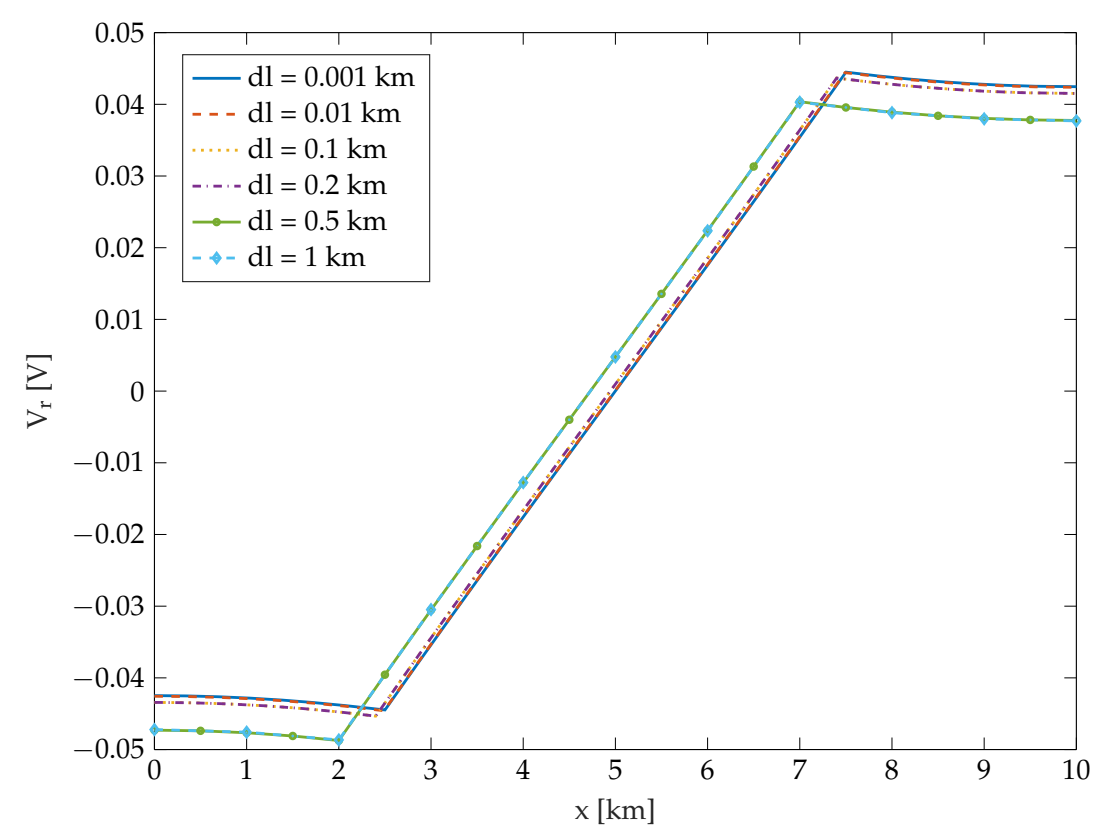

Figure 3. Potential distribution along rail for segments of different lengths (model with lumped parameters).

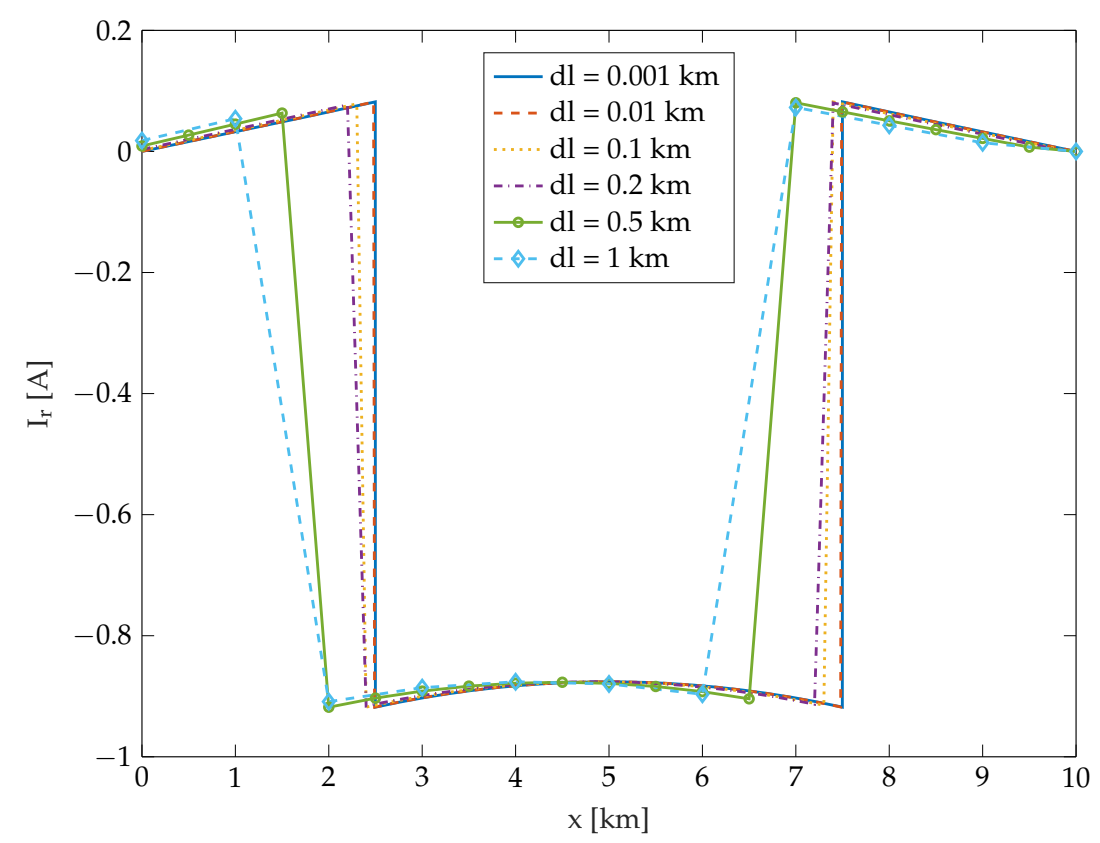

Figure 4. Current distribution along rail for segments of different lengths (model with lumped parameters). 


\section{Scalar Potential of Electric-Flow Field in the Ground Due to Stray Currents}

\subsection{General Considerations}

Rails are one of the elements of an electric D.C. traction circuit. Because they are not fully isolated from the ground, part of the current flows through the ground. This current generates an electric-flow field in the ground that is characterized by a scalar potential. The earth potential can be calculated according to earth-return theory. The equivalent rail (conductor with earth return carrying a longitudinal current) can be treated as a set of current elements of elementary length $\mathrm{d} \tau$. From each element, an elementary leakage current $-\frac{\mathrm{d} I_{r}(\tau)}{\mathrm{d} \tau}$ flows, producing in an observation point $P$ elementary scalar potential $\mathrm{d} V_{e}^{0}$ :

$$
d V_{e}^{0}(P)=\frac{-\frac{d I_{r}(\tau)}{d \tau}}{2 \pi \gamma r}
$$

where $\gamma$ is soil conductivity.

Assuming that the rail is located on the ground surface with conductivity $\gamma$, and that longitudinal current $I_{r}(x)$ flows along the rail, the scalar potential at an observation point $P(x, y, z)$ caused by leakage current from a finite-length rail (from $x_{1}$ to $x_{2}$ ) insulated at both ends and supplied by $I_{S}$ current at point $x=x_{s}$ can be obtained [24] from the following relation:

$$
\begin{aligned}
& V_{e}^{0}(P)=\frac{I_{s} \Gamma_{r}}{4 \pi \gamma}\left[-e^{-\Gamma_{r} x_{s}} \int_{x_{1}}^{x_{s}} \frac{e^{\Gamma_{r} \tau}}{\sqrt{(x-\tau)^{2}+y^{2}+z^{2}}} d \tau+\right. \\
& -e^{\Gamma x_{s}} \int_{x_{s}}^{x_{2}} \frac{e^{-\Gamma_{r} \tau}}{\sqrt{(x-\tau)^{2}+y^{2}+z^{2}}} d \tau+ \\
& -\frac{\cosh \Gamma_{r}\left(x_{2}-x_{s}\right)}{\sinh \Gamma_{r} L} e^{\Gamma_{r} x_{1}} \int_{x_{1}}^{x_{2}} \frac{e^{-\Gamma_{r} \tau}}{\sqrt{(x-\tau)^{2}+y^{2}+z^{2}}} d \tau+ \\
& \left.-\frac{\cosh \Gamma_{r}\left(x_{s}-x_{1}\right)}{\sinh \Gamma_{r} L} e^{-\Gamma_{r} x_{2}} \int_{x_{1}}^{e^{\Gamma_{r} \tau}} \frac{\sqrt{(x-\tau)^{2}+y^{2}+z^{2}}}{\sqrt{(x-1}}\right]
\end{aligned}
$$

Total earth potential at observation point $P(x, y, z)$ can be calculated using the superposition principle (if there are a number of loads and substations).

\subsection{Calculation of Earth Potential Generated by D.C. Traction of Complex Geometry}

In practice, the electric-traction route creates a complex geometric structure, and analysis of the electric-flow field generated in the ground by stray currents flowing from electric-traction rails is a difficult problem.

However, the method of determining the scalar potential generated by the current flowing from a finite-length equivalent rail supplied by the current (Figure 1b), as described in the previous section, may be used to develop a calculation model that takes into account the complex configuration of the electric-traction route and the larger number of traction substations and electric vehicles at any location. Using the segmental approximation of a complex railway route and the superposition principle, the potential in any observation point in the ground can be calculated.

To determine the ground potential in the area of D.C. tracks with a complex geometry, it is necessary to approximate the equivalent rail with a set of straight-line segments. Consider the line segment (modeled as a current path) shown in the Cartesian reference system $x, y, z$ in Figure 5. 


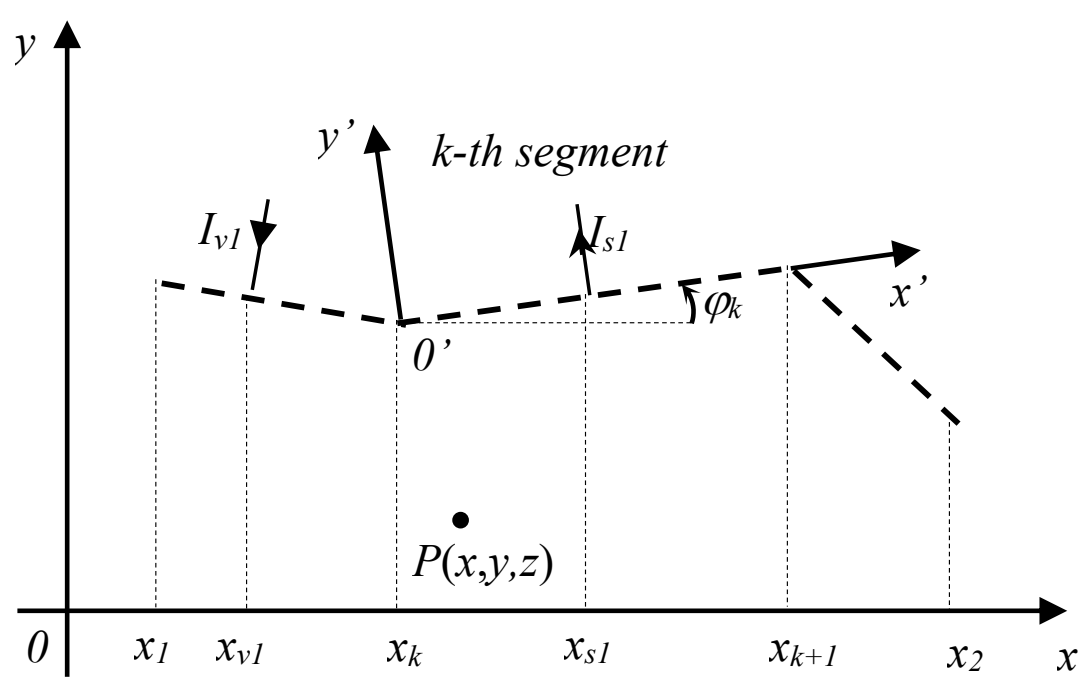

Figure 5. Route of complex geometry in reference system-top view.

Reference coordinate system $x, y, z$ can be freely positioned in space, but it is reasonable to place the $x y$ plane on the ground surface. An additional (local) system of rectangular coordinates $x^{\prime}, y^{\prime}, z^{\prime}$ is inserted, and the concerned segment lies on the abscissa axis, whereas the beginning of segment $k$ lies in the origin of the additional system of coordinates. Between the $x$-axis of the reference system (unprimed) and the $x^{\prime}$-axis of the additional coordinate system (primed), angle $\varphi_{k}$ (measured anticlockwise) exists.

For example, the potential in the ground at a given point of observation $P(x, y, z)$ produced by the current flowing in the $k$ th segment is determined on the basis of the relation in Equation (6) assuming that the segment with length $l_{k}$ is supplied with a substation current $I_{s}$. After transforming the coordinates of the observation point (transposition and rotation), calculations are carried out in the local coordinate system according to Equation (7):

$$
\begin{aligned}
& V_{e k}^{0}(P)=\frac{I_{s} \Gamma_{r}}{4 \pi \gamma}\left[-e^{-\Gamma_{r} x_{s}^{\prime}} \int_{0}^{x_{s}^{\prime}} \frac{e^{\Gamma_{r} \tau}}{\sqrt{\left(x^{\prime}-\tau\right)^{2}+y^{\prime 2}+z^{\prime 2}}} d \tau+\right. \\
& -e^{\Gamma_{r} x_{s}^{\prime}} \int_{x_{s}^{\prime}}^{l_{k}} \frac{e^{-\Gamma_{r} \tau}}{\sqrt{\left(x^{\prime}-\tau\right)^{2}+y^{\prime 2}+z^{\prime 2}}} d \tau+ \\
& -\frac{\cosh \Gamma_{r}\left(x_{2}^{\prime}-x_{s}^{\prime}\right)}{\sinh \Gamma_{r} L} e^{\Gamma_{r} x_{1}^{\prime}} \int_{0}^{l_{k}} \frac{e^{-\Gamma_{r} \tau}}{\sqrt{\left(x^{\prime}-\tau\right)^{2}+y^{\prime 2}+z^{\prime 2}}} d \tau+ \\
& \left.-\frac{\cosh \Gamma_{r}\left(x_{s}^{\prime}-x_{1}^{\prime}\right)}{\sinh \Gamma_{r} L} e^{-\Gamma_{r} x_{2}^{\prime}} \int_{0}^{l_{k}} \frac{e^{\Gamma_{r} \tau}}{\sqrt{\left(x^{\prime}-\tau\right)^{2}+y^{\prime 2}+z^{\prime 2}}} d \tau\right]
\end{aligned}
$$

It should be also noted that, for each rail segment with leakage current, a new coordinate system and transformation of appropriate boundary conditions, as well as coordinates of all substations and locomotives, have to be applied.

If the number of substations and loads (vehicles) along the traction route is $N$, and the equivalent rail is divided into $n$ line segments, the total potential at any observation point can be obtained according to the superposition principle from the following relation:

$$
V_{e}^{0}(P)=\sum_{k=1}^{n} \sum_{m=1}^{N} V_{e k, m}^{0}(P)
$$




\section{Current and Potential along Pipeline Buried in D.C. Stray-Current Area}

\subsection{Pipeline as Circuit with Distributed Parameters}

Current and potential along a pipeline (infinitely long earth-return circuit) buried in electric-flow field $\left(E(x)=\mathrm{d} V_{e}^{0} / \mathrm{d} x\right)$ due to stray currents can be obtained from relation [3,4]:

$$
I(x)=\frac{Y_{p}}{2}\left[e^{-\Gamma_{p} x} \int_{-\infty}^{x} V_{e}^{0}(v) e^{\Gamma_{p} v} d v-e^{\Gamma_{p} x} \int_{x}^{\infty} V_{e}^{0}(v) e^{-\Gamma_{p} v} d v\right],
$$

where $Y_{p}$, p. u. 1. (per unit length) pipeline shunt admittance and $\Gamma_{p}$ is the pipeline propagation constant. Pipeline potential takes form:

$$
V(x)=\frac{\Gamma_{p}}{2}\left[e^{-\Gamma_{p} x} \int_{-\infty}^{x} V_{e}^{0}(v) e^{\Gamma_{p} v} d v+e^{\Gamma_{p} x} \int_{x}^{\infty} V_{e}^{0}(v) e^{-\Gamma_{p} v} d v\right]
$$

on the assumption that potential $V_{e}^{0}$ is finite when $x$ approaches infinity. The numerical solution of equations used in this method is complicated. It increases calculation time, and special algorithms must be applied.

\subsection{Lumped-Parameter Model of Energized Pipeline by Controlled-Voltage Source}

To analyze the current that flows into a pipeline, the described method in Section 2.2 can be used [13]. The pipeline, similar to the rail in the previous section, can be modeled as a circuit with lumped parameters. The scalar potential of the electric field can be modeled using controlled-voltage sources $\left(V_{e}^{0}\right)$ (controlled by leakage currents from rails according to Equations (5) and (6), with no leakage currents and no earth scalar potential $V_{e}^{0}$ ) acting in shunt branches of the $\pi$-two ports, as shown in Figure 6 [24].

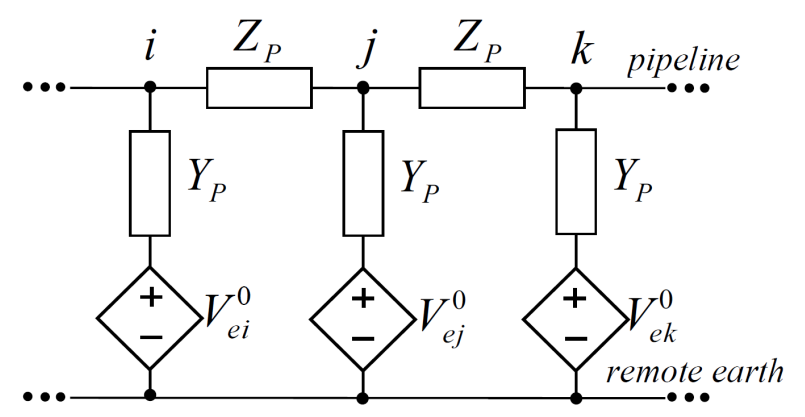

Figure 6. $\pi$-two-port model of pipeline with controlled-voltage source representing pipeline energization by earth scalar potential.

An alternative to this method is to determine the pipeline-energization parameters in a different way. One way is to determine the conductive coupling in the pipeline-rail system using mutual conductances between both earth-return circuits. On this basis, and knowing values of the leakage current from the rail, it is possible to determine the voltage value of controlled-voltage source $V_{e_{a p p r o x}}^{0}$ supplying the pipeline:

$$
V_{e_{a p p r o x}}^{0}=\frac{I_{r e i}}{G_{r p} \cdot \Delta l_{i}},
$$


where $I_{r e}$ is the leakage current from rail calculated from the relation in Equation (4); and $G_{r p}$ is the mutual conductance p. u. l. between rail and pipeline given by [3]:

$$
G_{r p}^{-1}=\frac{1}{\pi \gamma} \ln \frac{1.12}{s_{r p} \sqrt{\Gamma_{r} \Gamma_{p}}}
$$

where $\Gamma_{r}$ is the rail-propagation constant; $\Gamma_{p}$ is the pipeline-propagation constant; $\gamma$ is the ground conductivity; and $s_{r p}$ is the distance:

$$
s_{r p}=\sqrt{\left(d_{r}-d_{p}\right)^{2}+a_{r p}^{2}}
$$

where $d_{p}$ is the burial depth of a pipeline; $d_{r}$ is the burial depth of a rail; and $a_{r p}$ is the horizontal distance between earth-return circuits.

\section{Incorporating Electrode Kinetics}

To fully model the response of the pipeline to D.C. traction stray currents, it is necessary to include in the simulation model presented in previous sections the kinematics of electrode reactions taking place on the metal surface in the soil electrolyte.

Electrode reactions belong to the electron-transfer group, and this process takes place at the electrode/solution interface. The measure of the electrode-reaction rate (oxidation and reduction reaction) is current density $J$. The resultant current flowing through the electrode is the algebraic sum of the positive anode current (current associated with oxidation reaction) and negative cathode current (current associated with reduction reaction).

Potential $V_{p}$ of an electrode through which a different current form $J_{0}$ flows (exchange-current density representing exchange-reaction rate) differs from equilibrium potential (steady-state potential) $V_{s}$ by a value called overpotential $\eta$ and by an ohm drop of potential in the soil and in pipeline-insulation defects $V_{I R}$ :

$$
V_{p}=V_{s}+\eta+V_{I R}
$$

In the works concerning problems of the influence of D.C. stray currents on underground metal structures, the phenomenon of polarization is generally omitted [34-36]. However, omission of electrochemical phenomena (kinetics of electrode reactions) occurring at the metal-soil electrolyte interface in the calculation of currents and potentials of the structure located in the areas affected by stray currents can lead to significant errors. The Butler-Volmer equation binds current density with activation polarization:

$$
J=J_{0}\left\{\exp \left[\frac{\alpha_{A} n F \eta}{R T}\right]-\exp \left[-\frac{\alpha_{C} n F \eta}{R T}\right]\right\},
$$

where $R$ is the gas constant $(R=8.3143 \mathrm{~J} /(\mathrm{mol} \cdot \mathrm{K})), T$ is absolute temperature $(\mathrm{K}), n$ is the number of electrons transferred by one ion, $F(F=96,500 \mathrm{C} / \mathrm{mol})$ is the Faraday constant, and $\alpha$ is the symmetry coefficient that describes the shape of the rate-controlling energy barrier (anodic and cathodic transfer coefficients $\alpha_{A}+\alpha_{C}=1$ ). As the cathodic transfer-coefficient value increases, reduction is favored and oxidation is not, and vice versa for anodic transfer coefficients. Transfer coefficients depend on the $\mathrm{pH}$ of the medium; in acidic conditions (low $\mathrm{pH}$ ), reduction is favored, which is revealed by an increase in $\alpha_{C}$.

The Butler-Volmer equation indicates that current density at any overpotential $\eta$ is the sum of cathodic and anodic current densities. It follows from this equation that, at the extreme condition of overpotential $\eta$ being highly negative, cathodic current density increases, while anodic current density becomes negligible. At this stage, the first term in Equation (15) becomes negligible, and overpotential $\eta$ for cathodic activation polarization can be obtained from the following relation:

$$
\eta=-2.3\left(\frac{R T}{\alpha n F}\right) \log \left(\frac{J}{J_{0}}\right)
$$


Similarly, at highly positive overpotentials, anodic current density is much higher than the cathodic, cathodic current density becomes negligible in Equation (15), and overpotential $\eta$ for anodic activation polarization becomes:

$$
\eta=2.3\left(\frac{R T}{\alpha n F}\right) \log \left(\frac{J}{J_{0}}\right)
$$

In general, under condition $|\eta|>=50 \mathrm{mV}$, the overpotential of an electrode can be calculated from the Tafel equation:

$$
\eta= \pm \beta \log \frac{J}{J_{0}}
$$

with the value of $\beta$ for electrochemical reactions ranging between 0.05 volts and 0.15 volts, and $J$ being total current density. Factor $\beta=2.3(\mathrm{RT} / \alpha \mathrm{nF})$ is called the Tafel slope (Tafel constant).

Taking into account the considerations of the previous sections, a lumped-parameter model of a pipeline affected by stray currents from a D.C. railway system was proposed to use in simulation process (Figure 7 [27]) where $R_{p}$ is the longitudinal resistance and $G_{p}$ is the. shunt conductance of pipeline section with length $\Delta l$. All elements of the lumped-parameters model except for voltage sources with source voltage $\eta$ representing overvoltage are linear. The calculation of potentials and currents in the simulation model was carried out iteratively, and the iterative process quickly converged.

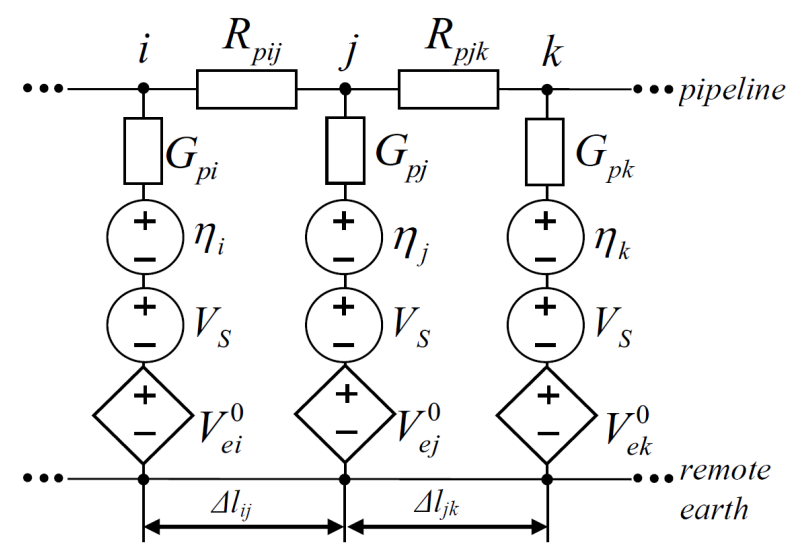

Figure 7. $\pi$-two-port model of pipeline with controlled-voltage source representing pipeline energization by earth scalar potential.

\section{Simulation Model Incorporating Monte Carlo Procedure}

The D.C. traction network and neighboring underground pipeline create systems of conductively connected earth-return circuits. On the basis of the analysis carried out earlier, it can be stated that changes in electrical and network parameters have huge impact on the distribution of stray currents in the ground. These changes can be divided into dynamic and spread over a longer period of time.The first type includes the location of the vehicle and current drawn from the traction network. These parameters go through large changes over small time periods. The second type go through smaller changes over large periods of time. There are the condition of the track (type of underlay under the rails, conductivity of the ground, etc.) and parameters such as soil conductivity and structure (seasonally changed), pipeline-insulation conductance, and pipe groundings, which influence electrical parameters (series and shunt resistances, mutual conductance, and propagation coefficients) of coupled earth-return circuits. In this paper, the impact of fast-changing parameters over time was considered: traction vehicle position and a load current. A similar solution was used in [26]. However, in that analysis, routes with complex geometry and electrochemical processes were not included.

The method presented in this paper allows determining cathodic and anodic regions along a buried pipeline of cathodic/anodic regions of pipeline located in the soil near a D.C. electric 
traction system. The simulation program used the deterministic models described in Sections $2-4$, combined with the probabilistic Monte Carlo procedure. Earth potential values were calculated with the distributed-parameter model. Potential and current distributions along the pipeline were determined by using a model with lumped parameters. Random variables, the electric vehicle current, and the vehicle position were used as input data to calculate the random characteristics of a pipeline, e.g., potential shift along a simulated metal installation. Calculated values composed statistical distributions, and each of them can be processed to calculate parameters such as maximum, minimum, median, and mean values.

The described numerical simulation was carried out using a MATLAB environment. Required input data, such as the number of substations and vehicles, electrical parameters of a pipeline, and D.C. traction with route course of the two installations, were read from an external .xls file. This allowed easily changing the route of a rail or a pipeline by providing appropriate coordinates of each node. Then, the position and current of the vehicle were drawn with a MATLAB pseudorandom number generator with adequate distribution. Numerous calculations for static systems allow obtaining many data for a specific variable, e.g., earth potential, pipeline potential to adjacent ground, leakage current, and pipeline overpotential.

\section{Calculation Examples}

\subsection{Example 1 (Case 1)}

To show the possibilities of the proposed method, two examples are presented. Overpotential along a pipeline located near the D.C. traction had its quantity calculated (Figure 8). Rail parameters were equal: $R_{r}=0.02 \Omega / \mathrm{km}$ and $G_{r}=0.76 \mathrm{~S} / \mathrm{km}$. In the first case, the rail was energized by a substation at Point $x_{s 1}=0 \mathrm{~km}$. Two variants were considered for this type of traction network supply. In the first option, the rail was energized by one vehicle at random position $x_{v 1}$. The second example considered two vehicles at random positions $x_{v 1}$ and $x_{v 2}$. In each case, the currents of vehicles was random in range $I_{v}=100-1000 \mathrm{~A}$, for each of them. Soil conductivity was equal to $\gamma=0.01 \mathrm{~S} / \mathrm{km}$. A pipeline with diameter $355.6 \mathrm{~mm}$ and electrical parameters $R_{p}=0.02 \Omega / \mathrm{km}, G_{p}=11 \mathrm{~S} / \mathrm{km}$ was buried at a depth of $1.0 \mathrm{~m}$. To calculate polarization effect, $\beta= \pm 0.1 \mathrm{~V}$, and $J_{0}=0.004 \mathrm{~A} / \mathrm{m}^{2}$ were assumed. Overpotential distribution along the tested pipeline was determined on the basis of 1000 tests. Simulation results are shown in Figures 9-13.

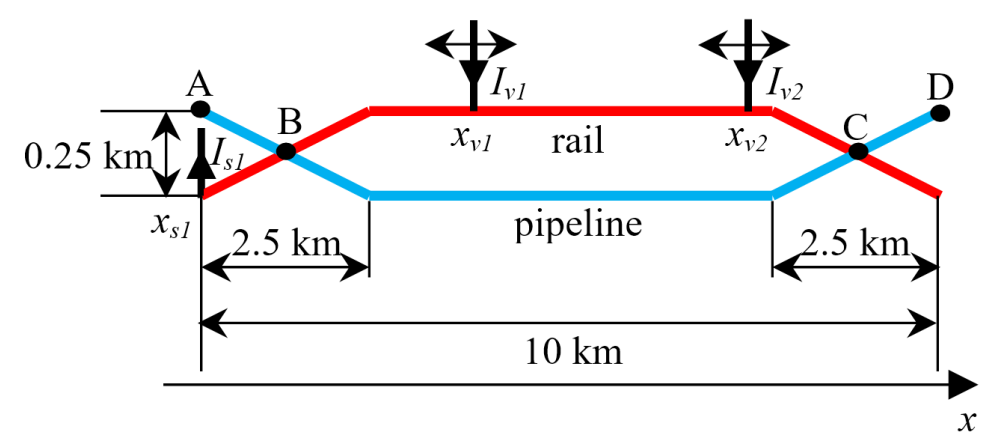

Figure 8. Layout of pipeline-railway track collocation (top view, no scale; Example 1).

To estimate the pipeline-corrosion risk, overpotential $\eta$ was observed along the structure. This parameter allowed defining anode and cathode zones. In the example, the average overpotential value had positive values in a range from $x=0.3 \mathrm{~km}$ to $x=2.5 \mathrm{~km}$. This was the anodic zone (corrosion hazard). In a range from $x=7.5 \mathrm{~km}$ to $x=9.6 \mathrm{~km}$, the overpotential had negative values (cathodic zone). The stray current in this region flowed into the pipeline. In the range of $x$ from $x=9.6 \mathrm{~km}$ to $x=10 \mathrm{~km}$, the average value of the overpotential distribution along the pipeline was positive, thus the anodic zone also occurred there. It can be observed that the number of vehicles do not 
change the shape of overpotential average value, but it gives only an amplifying effect. Comparison of average overpotential value distribution along the pipeline for different numbers of vehicles is shown in Figure 9.

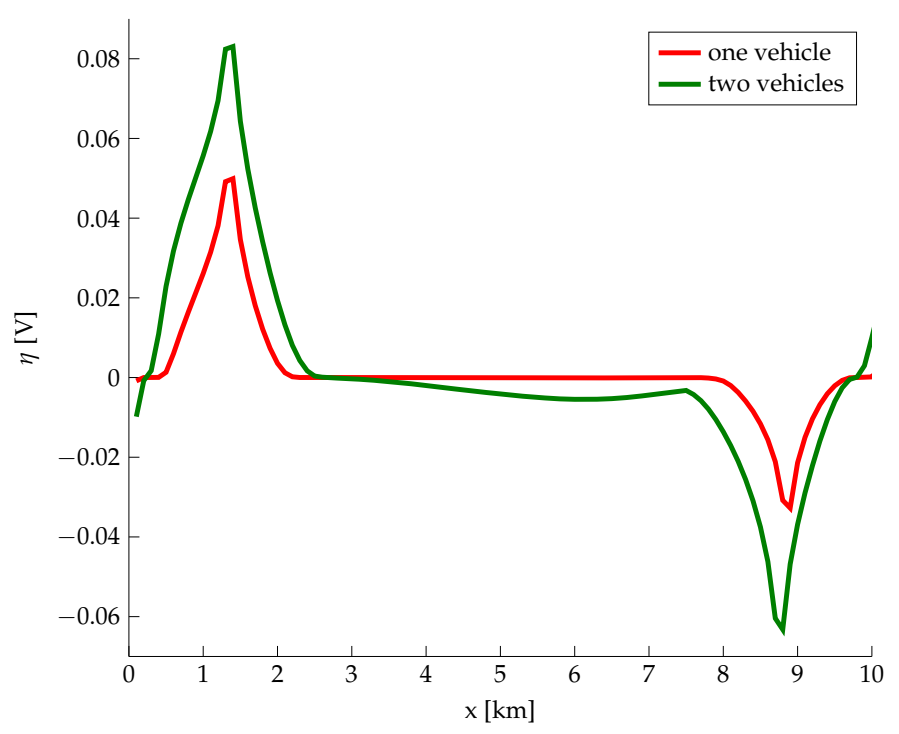

Figure 9. Overpotential distribution along pipeline-average value (for one station).

In addition, for option with two vehicles, overpotential values were observed at selected points of the structure (Points A-D) presented in Figure 8. The presented histograms allowed frequency assessment of the occurrence of a specific overpotential value for all drawn samples. It was possible to observe unfavorable values at Points $\mathrm{B}(x=1.25 \mathrm{~km})$ and $\mathrm{D}(x=10 \mathrm{~km})$. This is very important because Point $\mathrm{D}$ is away from the station and, using standard deterministic methods, the specified overpotential value could be underestimated. At Points A and C, the overpotential sign was negative or zero for all figures. Corrosion risk at these points was very small. Figures 10-13 show the histograms of pipeline potential at Points A-D.

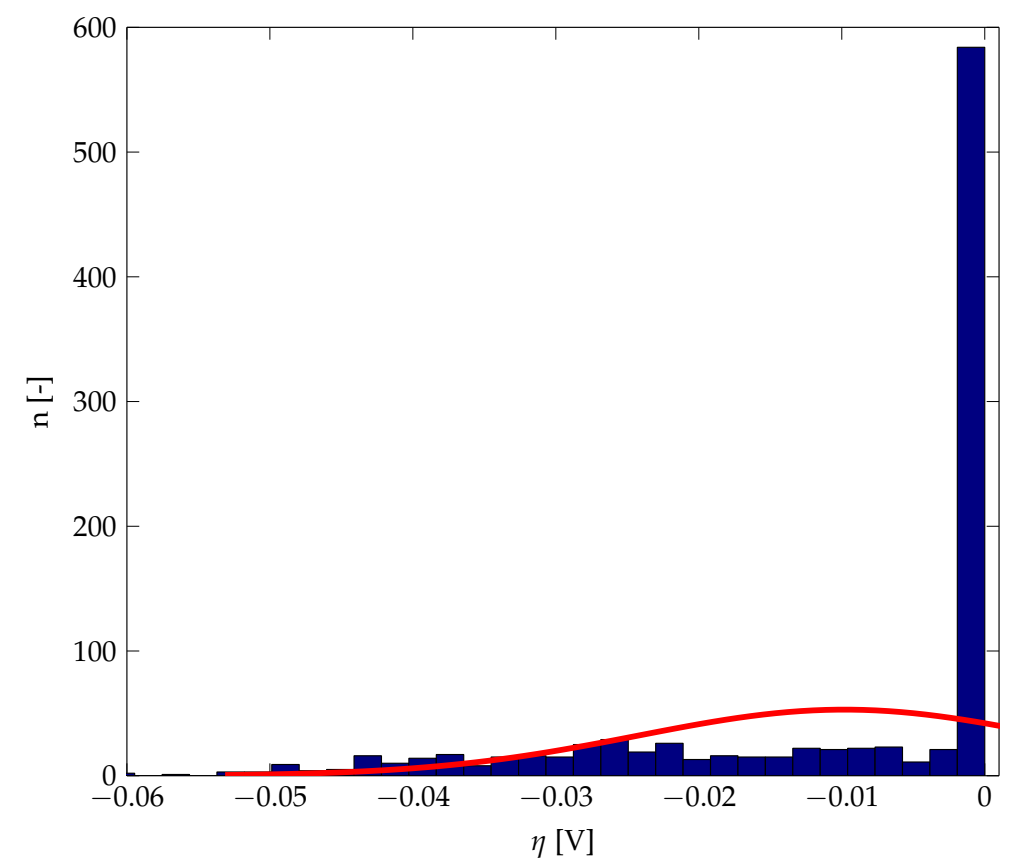

Figure 10. Pipeline overpotential value at Point $\mathrm{A}(x=0 \mathrm{~km})$ for one station at Point $x_{s}=0 \mathrm{~km}$ and two vehicles; $n$, number of occurrences of a given value of $\eta$. 


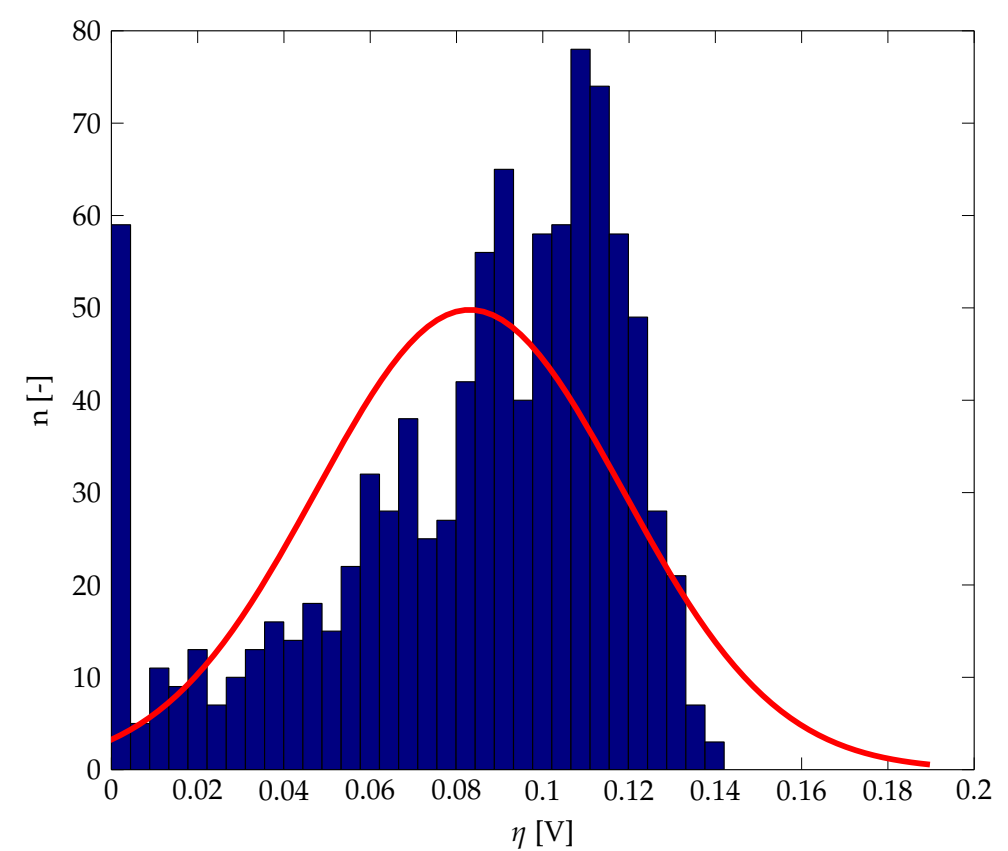

Figure 11. Pipeline overpotential value at Point $\mathrm{B}(x=1.25 \mathrm{~km})$ for one station at Point $x_{s}=0 \mathrm{~km}$ and two vehicles.

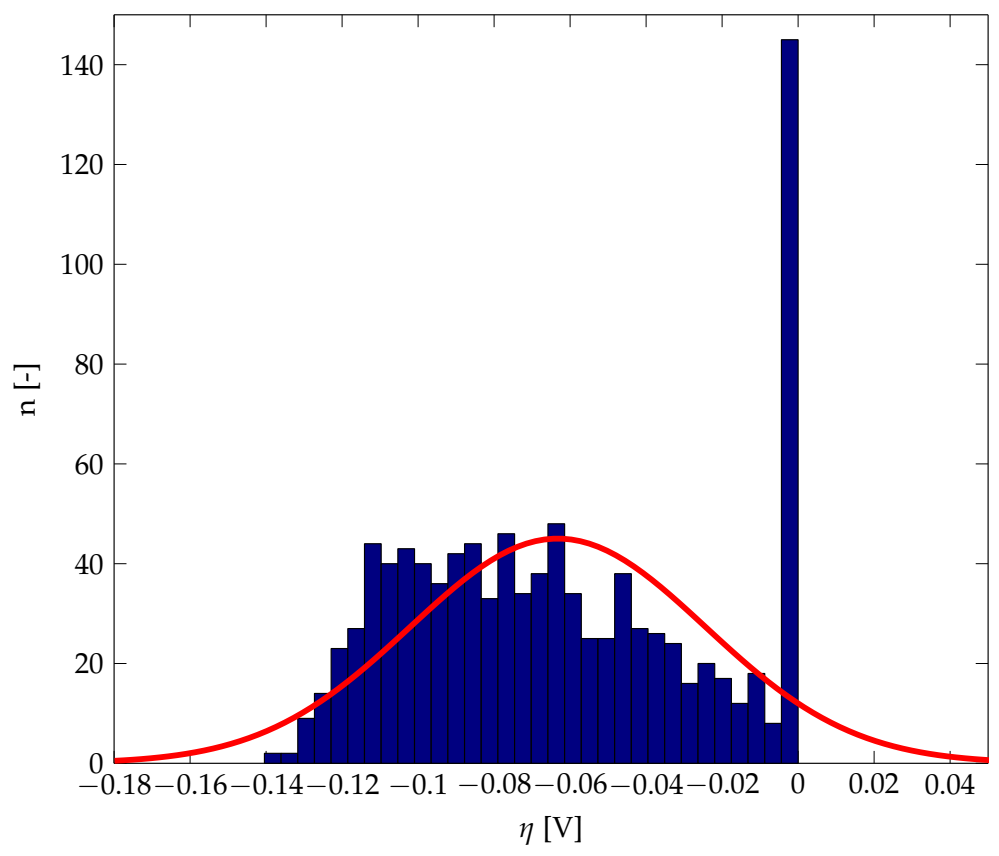

Figure 12. Pipeline overpotential value at Point $C(x=8.75 \mathrm{~km})$ for one station at Point $x_{s}=0 \mathrm{~km}$ and two vehicles.

\subsection{Example 2 (Case 2)}

To check the effect of the substation position, Example 2 is presented. In contrast to Example 1, the substation was located at Point $x_{s 1}=5 \mathrm{~km}$ (Figure 14). Calculations were carried out only for the case with two vehicles.

In this case, the average value of overpotential along the pipeline is several times lower than in Example 1 (Figure 15). The highest overpotential value is reached near the substation and it is about $\eta=0.007 \mathrm{~V}$. At observation Points B and D, the overpotential values are negative, which suggests that the pipeline in these places is not threatened by electrochemical corrosion. 


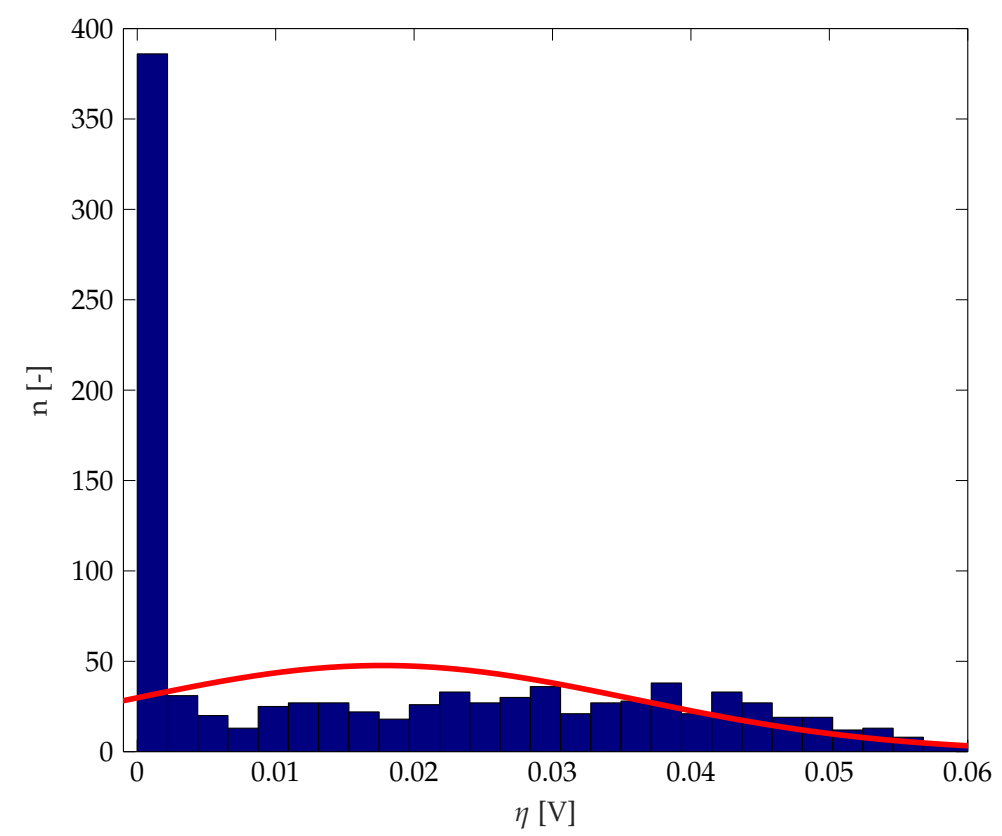

Figure 13. Pipeline overpotential value at Point $\mathrm{D}(x=10 \mathrm{~km})$ for one station at Point $x_{s}=0 \mathrm{~km}$ and two vehicles.

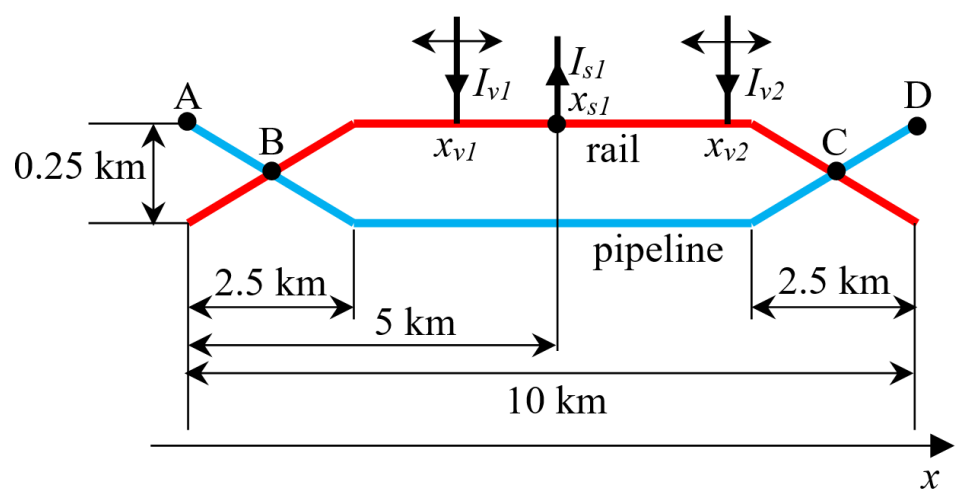

Figure 14. Pipeline layout-railway track collocation (top view, no scale; Example 2).

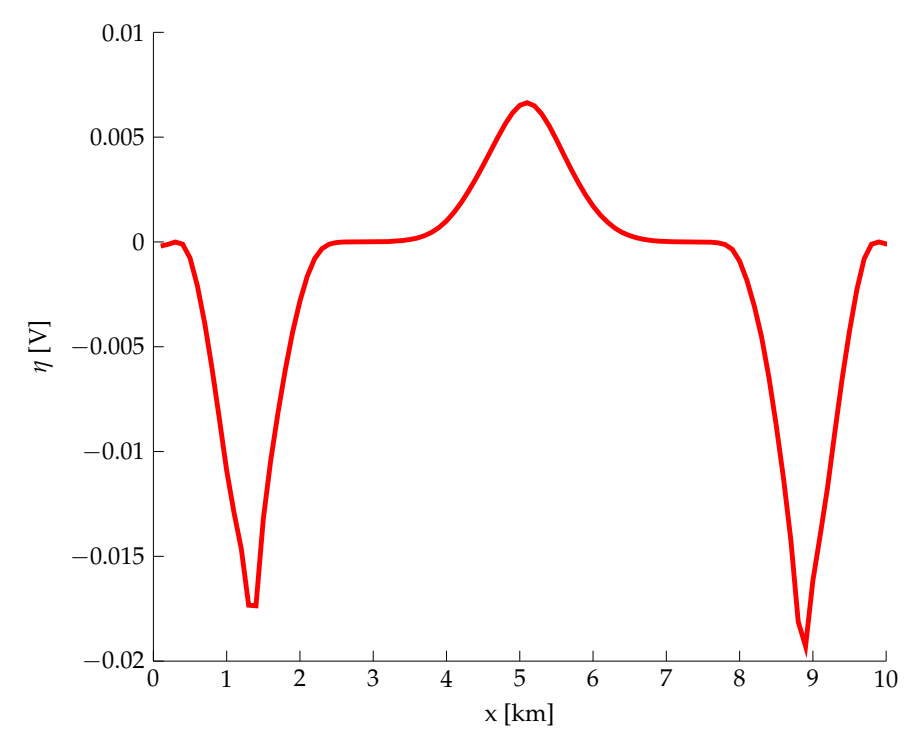

Figure 15. Overpotential distribution along pipeline-average value (for one station at point $x_{s}=5 \mathrm{~km}$ ). 
Overpotential values at selected points of the structure (Points A-D) are presented in Figures 16-19. Based on this observation of overpotential histograms, it can be concluded that Points $\mathrm{B}$ and $\mathrm{D}$ are also at risk of electrochemical corrosion, because about $40 \%$ of the obtained overpotential values are positive. Therefore, observing only the average overpotential value is insufficient.

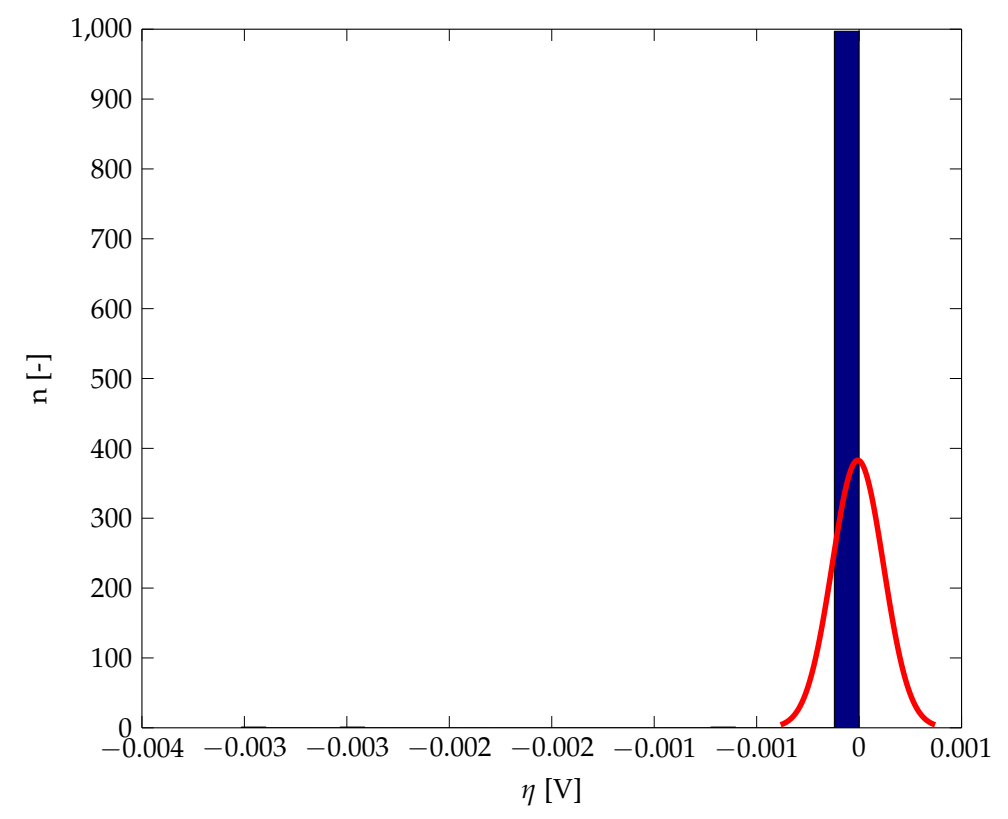

Figure 16. Pipeline overpotential value at Point $\mathrm{A}(x=0 \mathrm{~km})$ for one station at Point $x_{s}=5 \mathrm{~km} ; n$, number of occurrences of given value of $\eta$.

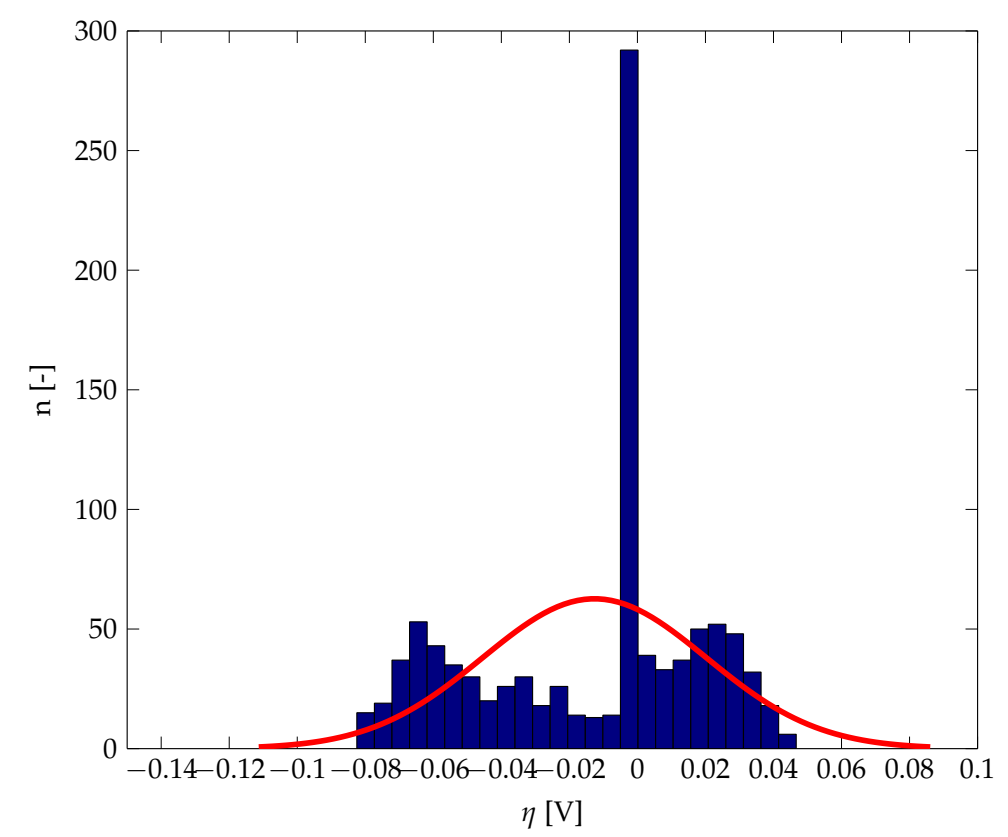

Figure 17. Pipeline overpotential value at Point $\mathrm{B}(x=1.25 \mathrm{~km})$ for one station at Point $x_{s}=5 \mathrm{~km}$.

\subsection{Example 3 (Case 3)}

To demonstrate the possibilities of the algorithm and the effect of the traction-system configuration, Example 3 is presented. In contrast to Examples 1 and 2, the traction network was bilaterally supplied. The first station is located at Point $x_{s 2}=0 \mathrm{~km}$ and the second at Point $x_{s 2}=10 \mathrm{~km}$ (Figure 20). 


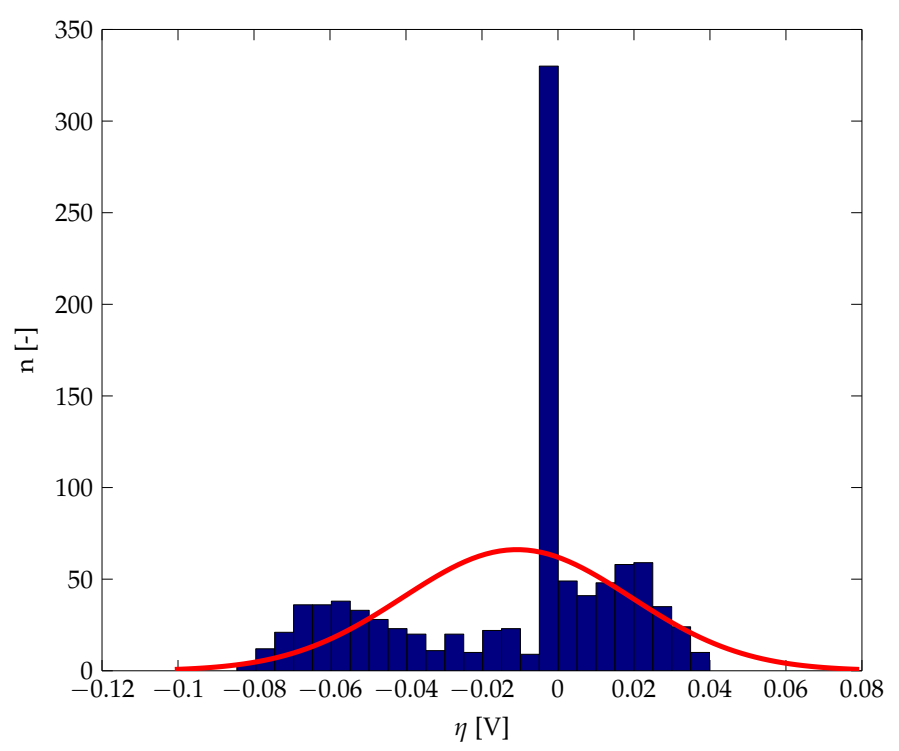

Figure 18. Pipeline overpotential value at Point $C(x=8.75 \mathrm{~km})$ for one station at Point $x_{s}=5 \mathrm{~km}$.

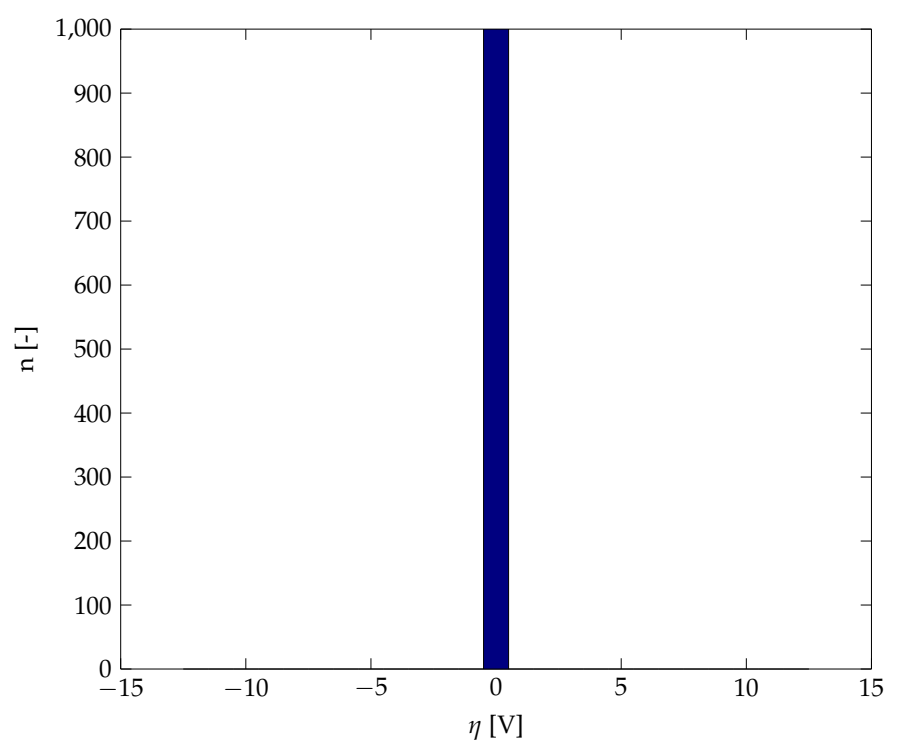

Figure 19. Pipeline overpotential value at Point $\mathrm{D}(x=10 \mathrm{~km})$ one station at Point $x_{s}=5 \mathrm{~km}$.

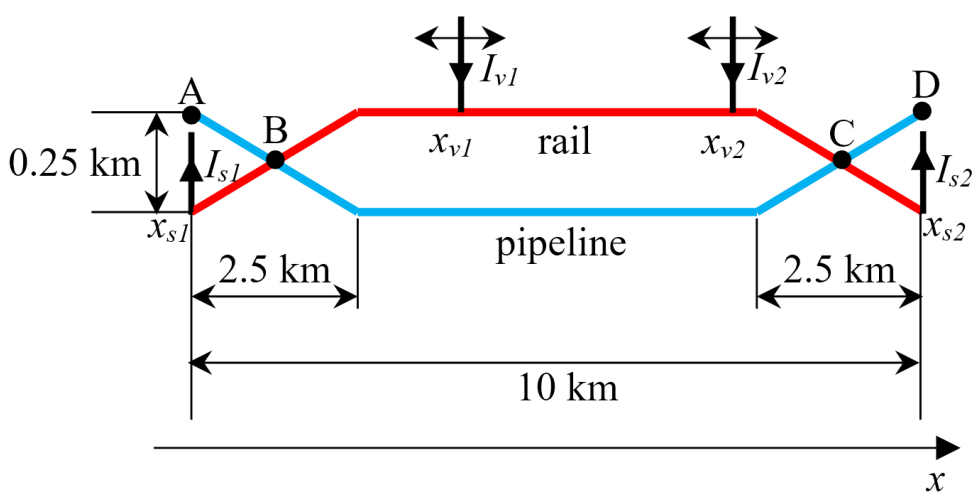

Figure 20. Pipeline layout-railway track collocation (top view, no scale; Example 3). 
Observation points were situated in the same places as in Example 1. Load currents of individual stations depended on the position of the vehicles. Figure 21 shows the average value of overpotential distribution along the pipeline.

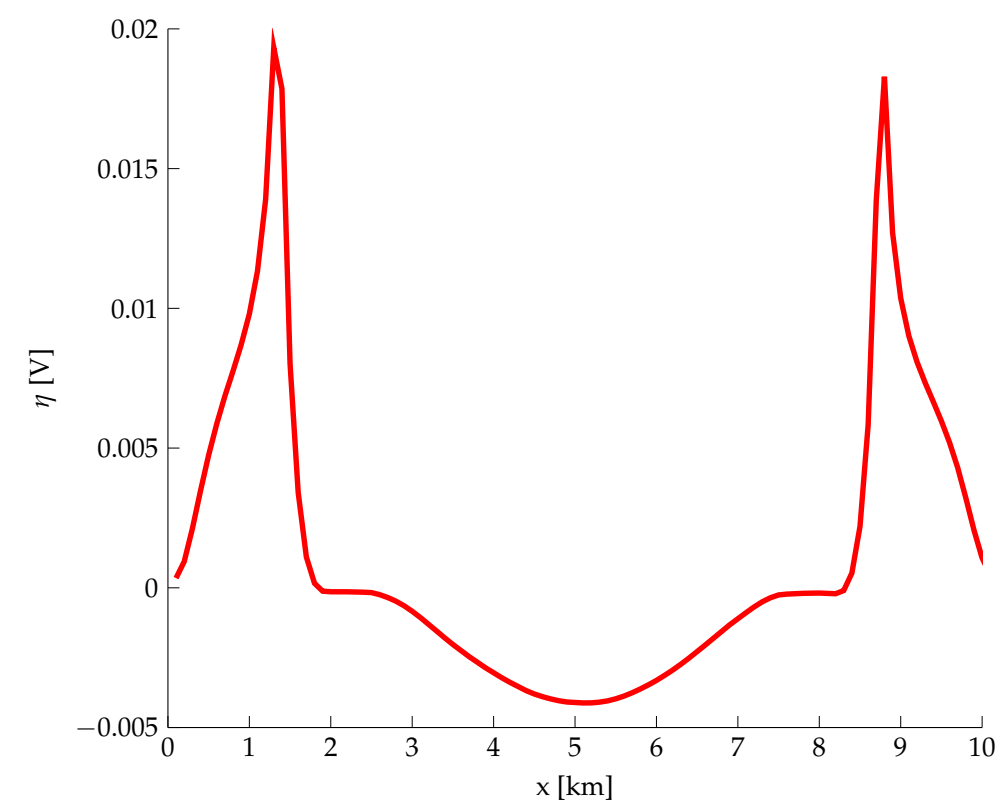

Figure 21. Overpotential distribution along the pipeline-average value (for two stations).

Figures 22-25 show the overpotential distribution at observation points. At Point $B$ in relation to Example 1, it can be seen that, for some samples, this parameter took negative values. Therefore, using only deterministic methods can lead to calculation mistakes because positive values of the examined quantity are more likely to occur. The most important change can be observe for Point $C$, where the overpotential value sign changed from negative to positive, which significantly increased the corrosion risk in this zone. At Points A and D, the overpotential value was nearly zero the entire time, but small positive values could sometimes be observed, thus it could also be dangerous for the pipeline.

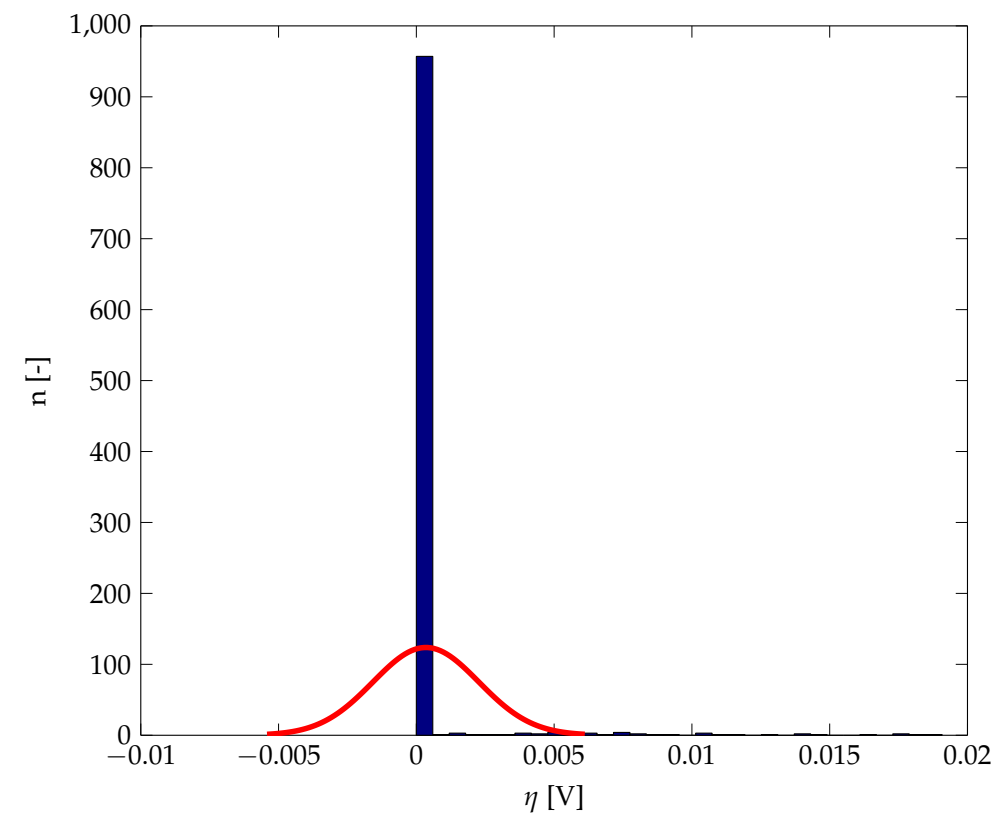

Figure 22. Pipeline overpotential value at Point A $(x=0 \mathrm{~km})$ for two stations; $n$, number of occurrences of given value of $\eta$. 


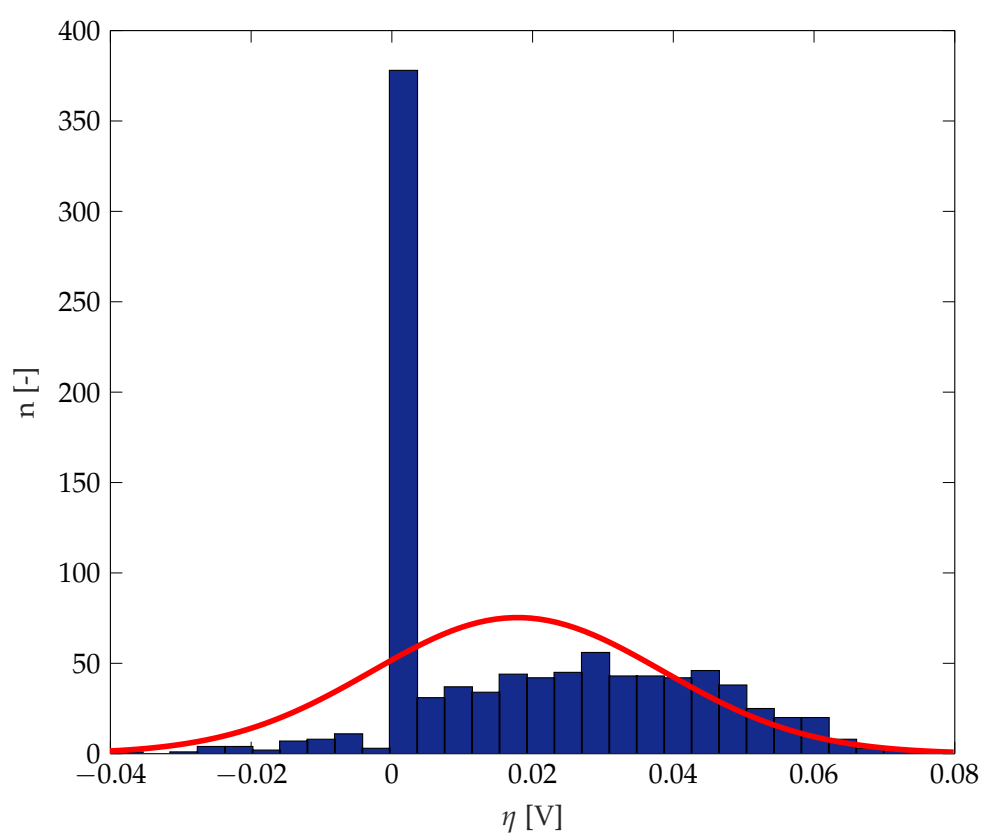

Figure 23. Pipeline overpotential value at Point $B(x=1.25 \mathrm{~km})$ for two stations.

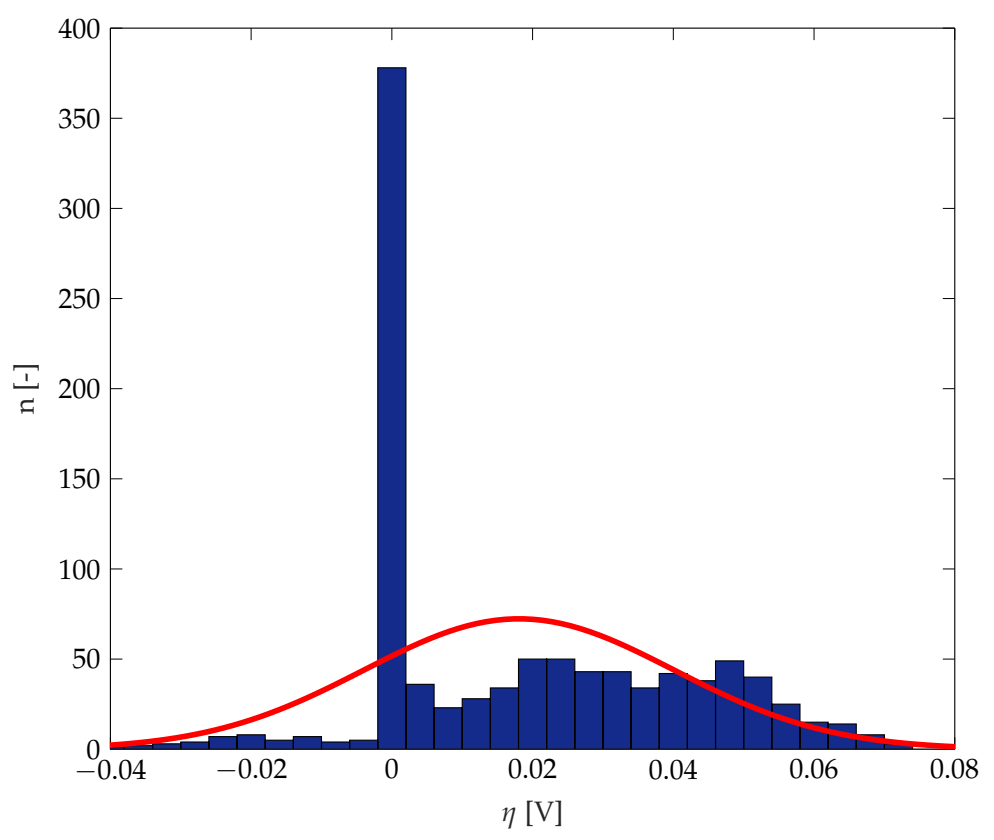

Figure 24. Pipeline overpotential value at Point $C(x=8.75 \mathrm{~km})$ for two stations.

\subsection{Result Comparison}

To assess the impact of the introduced changes in the second and third example in relation to Example 1, we compared the obtained results. Table 1 presents the simulation results for all cases. The compared parameters are minimum, maximum, average, and median values. A comparison of the mean overpotential value is presented in Figure 26.

The most important change in Examples 2 and 3 in relation to Example 1 is a reduction of overpotential average value. Between Cases 1 and 2, the difference is the reversal of the overpotential sign at Point $C$ for a traction system supplied from two stations. The average value of overpotential at Points B and C for Example 3 was equal and four times smaller than the value at Point B for Example 1. Overpotential values at the ends of the pipeline were largely overcome. Nevertheless, the obtained values indicated the anodic zone. 


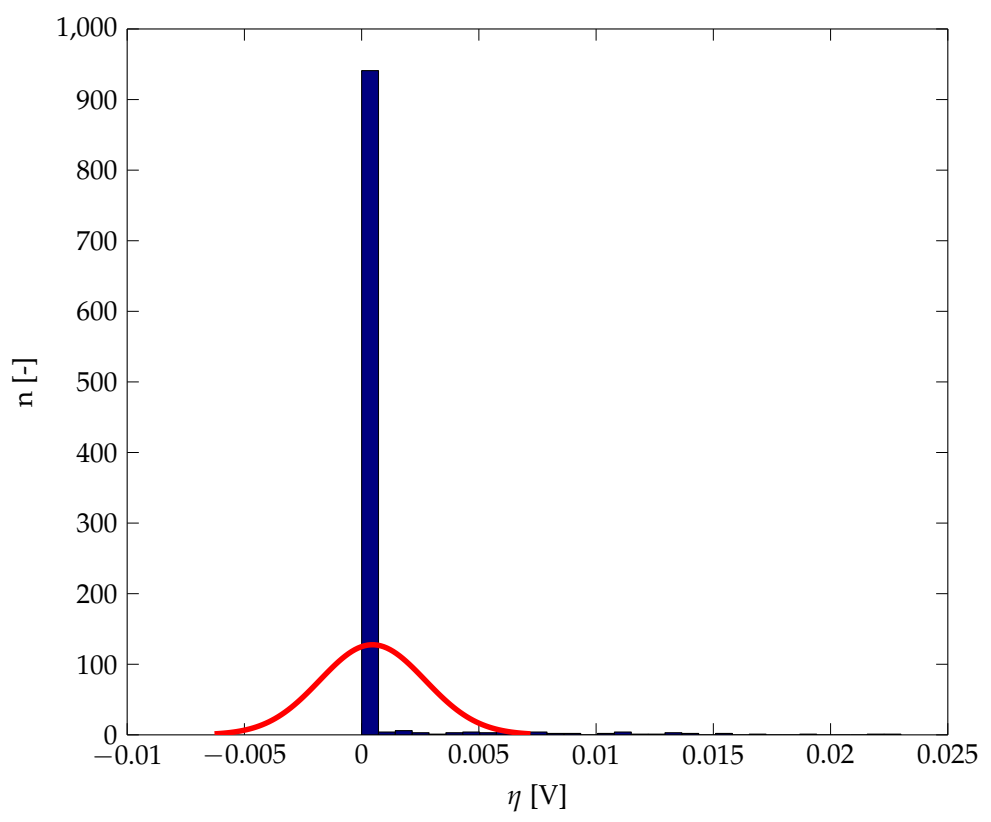

Figure 25. Pipeline overpotential value at Point D $(x=10 \mathrm{~km})$ for two stations.

Table 1. Comparison of overpotential values for three presented examples (two vehicles on route).

\begin{tabular}{|c|c|c|c|c|c|c|c|c|c|c|c|c|}
\hline \multirow{3}{*}{ Point } & \multicolumn{3}{|c|}{ Min [V] } & \multicolumn{3}{|c|}{$\operatorname{Max}[\mathrm{V}]$} & \multicolumn{3}{|c|}{ Average [V] } & \multicolumn{3}{|c|}{ Median [V] } \\
\hline & \multicolumn{3}{|c|}{ Example } & \multicolumn{3}{|c|}{ Example } & \multicolumn{3}{|c|}{ Example } & \multicolumn{3}{|c|}{ Example } \\
\hline & 1 & 2 & 3 & 1 & 2 & 3 & 1 & 2 & 3 & 1 & 2 & 3 \\
\hline A & -0.061 & -0.025 & 0.000 & 0.000 & 0.026 & 0.019 & -0.010 & 0.000 & 0.000 & 0.000 & 0.000 & 0.000 \\
\hline B & 0.000 & -0.111 & -0.050 & 0.142 & 0.071 & 0.071 & 0.083 & -0.018 & 0.018 & 0.092 & -0.011 & 0.013 \\
\hline $\mathrm{C}$ & -0.140 & -0.107 & -0.050 & 0.000 & 0.067 & 0.068 & -0.063 & -0.018 & 0.018 & -0.067 & -0.006 & 0.014 \\
\hline $\mathrm{D}$ & 0.000 & -0.023 & 0.000 & 0.070 & 0.018 & 0.023 & 0.018 & 0.000 & 0.000 & 0.013 & 0.000 & 0.000 \\
\hline
\end{tabular}

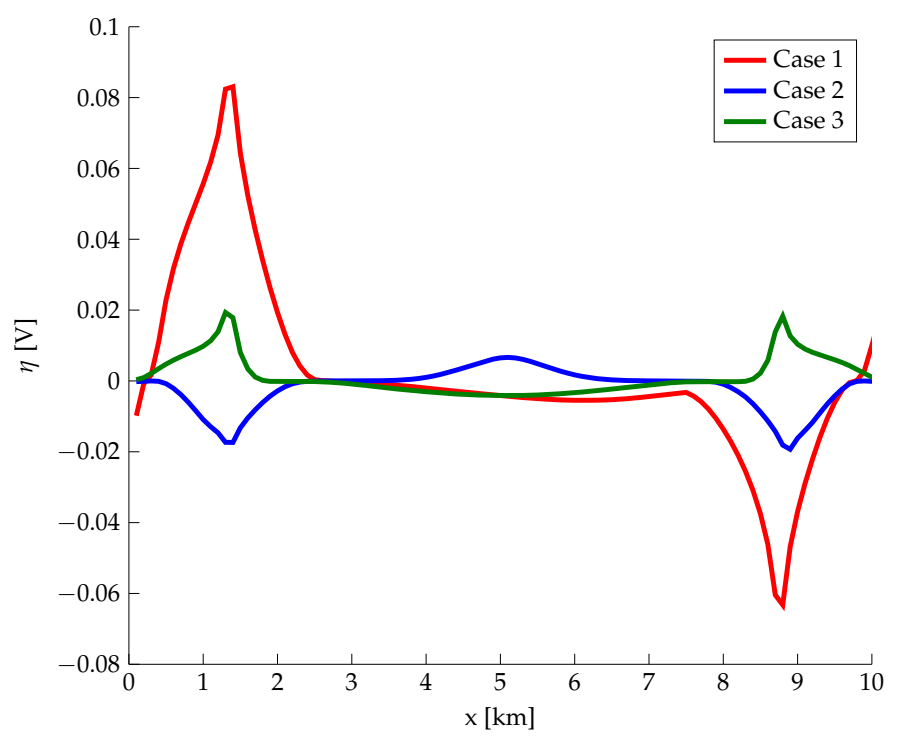

Figure 26. Overpotential distribution along pipeline-average values (comparison for two vehicles on route). 


\section{Conclusions}

Globally, electric-rail transport is very popular, and its negative impact on underground metal installations can be very dangerous, and threaten lives and property. That is why determining the scale of danger is very important. The proposed methods for determining the spread of stray currents have until now omitted dynamic changes of network parameters, such as vehicle location and load current, or they are used in systems with simple rail and pipeline geometry.

The presented method allows calculating the polarization effect (nonlinear electrochemical phenomenon on the interface of metal-soil electrolyte) in underground metal installations, e.g., pipelines. The position and current of the vehicle are random variables. This approach allows determining occurrence range and frequency of responsible parameters for the course of the electrochemical-corrosion process. In the presented examples, it was shown that, at some points of the tested installations, the obtained results took opposite signs, which means that, in those zones, the current-flow direction may change, which, in the case of deterministic methods, can make them difficult to detect.

The presented research results show that a risk of electrochemical corrosion depends mainly of supplying the traction network. A change in the number of vehicles on the route does not affect the shape of the average value of overpotential, but only generates the effect of amplification, as shown in Example 1. For the presented geometrical rail-pipeline situation, relocation of the substation or the use of a second substation resulted in a fourfold reduction of the average overpotential value along the pipeline. However, the nature of the impact changed, which increased the potential number of zones along the pipeline with risk of electrochemical corrosion. The obtained test results are very important because they show how much the flow of stray currents depends on the location of the substations. Therefore, during planned repairs and long shutdowns of the substations, unexpected damage of underground metal installations that previously worked properly and with low risk of stray current corrosion is possible.

The presented simulation method can be used as a predictive tool, especially at the design stage, to estimate the level of stochastic stray-current interference to be expected on underground metal pipelines located near D.C. traction.

Author Contributions: Conceptualization, W.M. and J.S.; methodology, W.M., J.S., and K.B.; software, J.S.; validation, W.M., J.S., and K.B.; formal analysis, J.S.; investigation, W.M. and J.S.; data curation, W.M. and J.S.; writing-original-draft preparation, W.M. and J.S.; writing-review and editing, K.B.; visualization, J.S.; and supervision, W.M.

Funding: This research was funded by the Polish government (grants number 04/42/SBAD/0483 and 04/42/SBAD/0495).

Conflicts of Interest: The authors declare no conflict of interest. The funders had no role in the design of the study; in the collection, analyses, or interpretation of data; in the writing of the manuscript; or in the decision to publish the results.

\section{References}

1. Protection Against Corrosion by Stray Current from Direct Current Systems; Technical Report EN-50162-2004; NSAI: Dublin, Ireland, 2004.

2. Railway Applications_Fixed Installations_Electrical Safety, Earthing and the Return Circuit_Part 2: Provisions Against the Effect of Stray Currents Caused by D.C. Traction systems; Technical Report EN-50122-2; NSAI: Dublin, Ireland, 2010.

3. Sunde, E.D. Earth Conduction Effects in Transmission Systems; Dover Publications Inc.: Mineola, NY, USA, 1949.

4. Machczynski, W. Simulation model for drainage protection of earth-return circuits laid in stray currents area. Electr. Eng. 2002, 84, 165-172. [CrossRef] 
5. Bortels, L.; Dorochenko, A.; Van den Bossche, B.; Weyns, G.; Deconinck, J. Three-dimensional boundary element method and finite element method simulations applied to stray current interference problems. A unique coupling mechanism that takes the best of both methods. Corrosion 2007, 63, 561-576. [CrossRef]

6. Brichau, F.; Deconinck, J. A numerical model for cathodic protection of buried pipes. Corrosion 1994, 50, 39-49. [CrossRef]

7. Metwally, I.; Al-Mandhari, H.; Nadir, Z.; Gastli, A. Boundary element simulation of DC stray currents in oil industry due to cathodic protection interference. Eur. Trans. Electr. Power 2007, 17, 486-499. [CrossRef]

8. Ogunsola, A.; Mariscotti, A. Electromagnetic Compatibility in Railways: Analysis and Management; Springer Science \& Business Media: Berlin, Germany, 2012; Volume 168.

9. Chen, Z.; Koleva, D.; van Breugel, K. A review on stray current-induced steel corrosion in infrastructure. Corros. Rev. 2017, 35, 397-423. [CrossRef]

10. Charalambous, C.A.; Cotton, I.; Aylott, P. A simulation tool to predict the impact of soil topologies on coupling between a light rail system and buried third-party infrastructure. IEEE Trans. Veh. Technol. 2008, 57, 1404-1416. [CrossRef]

11. Charalambous, C.A. Comprehensive Modeling to Allow Informed Calculation of DC Traction Systems' Stray Current Levels. IEEE Trans. Veh. Technol. 2017, 66, 9667-9677. [CrossRef]

12. Charalambous, C.A.; Aylott, P.; Buxton, D. Stray current calculation and monitoring in DC mass-transit systems: Interpreting calculations for real-life conditions and determining appropriate safety margins. IEEE Veh. Technol. Mag. 2016, 11, 24-31. [CrossRef]

13. Czarnywojtek, P.; Machczyński, W. Computer simulation of responses of earth-return circuits to the AC and DC external excitation. Eur. Trans. Electr. Power 2003, 13, 173-183. [CrossRef]

14. Cerman, A.; Janíček, F.; Kubala, M. Resistive-type network model of stray current distribution in railway DC traction system. In Proceedings of the 16th International Scientific Conference on Electric Power Engineering (EPE), Kouty nad Desnou, Czech Republic, 20-22 May 2015; pp. 364-368.

15. Zaboli, A.; Vahidi, B.; Yousefi, S.; Hosseini Biyouki, M.M. Effect of control methods on calculation of stray current and rail potential in DC-electrified railway systems. In Proceedings of the 4th International Conference on Recent Advances in Railway Engineering (ICRARE2015), Tehran, Iran, 17-18 May 2015.

16. Zaboli, A.; Vahidi, B.; Yousefi, S.; Hosseini-Biyouki, M.M. Evaluation and control of stray current in DC-electrified railway systems. IEEE Trans. Veh. Technol. 2016, 66, 974-980. [CrossRef]

17. Fichera, F.; Mariscotti, A.; Ogunsola, A.; Sandrolini, L. Comparison of distributed and lumped parameters stray current models. In Proceedings of the 2013 Africon, Pointe-Aux-Piments, Mauritius, 9-12 September 2013; pp. 1-5.

18. Fichera, F.; Mariscotti, A.; Ogunsola, A. Evaluating stray current from DC electrified transit systems with lumped parameter and multi-layer soil models. In Proceedings of the Eurocon 2013, Zagreb, Croatia, 1-4 July 2013; pp. 1187-1192.

19. Jabbehdari, S.; Mariscotti, A. Distribution of stray current based on 3-Dimensional earth model. In Proceedings of the 2015 International Conference on Electrical Systems for Aircraft, Railway, Ship Propulsion and Road Vehicles (ESARS), Aachen, Germany, 3-5 March 2015; pp. 1-6.

20. Charalambous, C.A.; Aylott, P. Dynamic stray current evaluations on cut-and-cover sections of DC metro systems. IEEE Trans. Veh. Technol. 2014, 63, 3530-3538. [CrossRef]

21. Xu, S.Y.; Li, W.; Wang, Y.Q. Effects of vehicle running mode on rail potential and stray current in DC mass transit systems. IEEE Trans. Veh. Technol. 2013, 62, 3569-3580.

22. Zhao, L.; Li, J.; Liu, M. Simulation and analysis of metro stray current based on multi-locomotives condition. In Proceedings of the 2016 35th Chinese Control Conference (CCC), Chengdu, China, 27-29 July 2016; pp. 9252-9258.

23. Ogunsola, A.; Mariscotti, A.; Sandrolini, L. Estimation of stray current from a DC-electrified railway and impressed potential on a buried pipe. IEEE Trans. Power Deliv. 2012, 27, 2238-2246. [CrossRef]

24. Machczynski, W.; Budnik, K.; Szymenderski, J. Assessment of dc traction stray currents effects on nearby pipelines. COMPEL Int. J. Comput. Math. Electr. Electron. Eng. 2016, 35, 1468-1477. [CrossRef]

25. Ogunsola, A.; Sandrolini, L.; Mariscotti, A. Evaluation of stray current from a DC-electrified railway with integrated electric-Electromechanical modeling and traffic simulation. IEEE Trans. Ind. Appl. 2015, 51, 5431-5441. [CrossRef] 
26. Lucca, G. Estimating stray current interference from DC traction lines on buried pipelines by means of a Monte Carlo algorithm. Electr. Eng. 2015, 97, 277-286. [CrossRef] 
27. Machczyński, W.; Szymenderski, J.; Budnik, K. Polarization potential along underground pipeline of complex geometry generated by stochastic stray currents from DC traction. In Proceedings of the 18th International Symposium on Electromagnetic Fields in Mechatronics, Electrical and Electronic Engineering (ISEF) Book of Abstracts, Lodz, Poland, 14-16 September 2017; pp. 1-2.

28. Mariscotti, A.; Pozzobon, P. Determination of the electrical parameters of railway traction lines: Calculation, measurement, and reference data. IEEE Trans. Power Deliv. 2004, 19, 1538-1546. [CrossRef]

29. Du, G.; Zhang, D.; Li, G.; Wang, C.; Liu, J. Evaluation of Rail Potential Based on Power Distribution in DC Traction Power Systems. Energies 2016, 9. [CrossRef]

30. Liu, L.; Yu, Z.; Jiang, Z.; Hao, J.; Liu, W. Observation Research on the Effect of UHVDC Grounding Current on Buried Pipelines. Energies 2019, 12. [CrossRef]

31. Machczyński, W.; Szymenderski, J. Stochastic stray currents effects on earth return circuits (underground pipelines). Ochrona przed Korozja 2016, 8, 273-278. [CrossRef]

32. Hill, R.; Brillante, S.; Leonard, P. Railway track transmission line parameters from finite element field modelling: Series impedance. IEE Proc. Electr. Power Appl. 1999, 146, 647-660. [CrossRef]

33. Hill, R.J.; Brillante, S.; Leonard, P. Railway-track transmission-line parameters from finite-element field modelling: Shunt admittance. IEE Proc. Electr. Power Appl. 2000, 147, 227-238. [CrossRef]

34. Von Baeckmann, W.; Schwenk, W. Handbuch des Kathodischen Korrosionsschutzes: Theorie und Praxis der Elektrochemischen Schutzverfahren; John Wiley \& Sons: Hoboken, NJ, USA, 2009.

35. International, N. Control of External Corrosion on Underground or Submerged Metallic Piping Systems; Number NACE SP0169-2013; NACE International: Houston, TX, USA, 2013.

36. Wang, X.; Wang, Z.; Chen, Y.; Song, X.; Yang, Y. Effect of a DC Stray Current on the Corrosion of X80 Pipeline Steel and the Cathodic Disbondment Behavior of the Protective 3PE Coating in 3.5NaCl Solution. Coatings 2019, 9. [CrossRef]

(C) 2019 by the authors. Licensee MDPI, Basel, Switzerland. This article is an open access article distributed under the terms and conditions of the Creative Commons Attribution (CC BY) license (http:/ / creativecommons.org/licenses/by/4.0/). 